\title{
¿ES EL DISCURSO RELIGIOSO ODIOSO POR RAZONES DE GÉNERO, ORIENTACIÓN E IDENTIDAD SEXUAL UN DISCURSO DE ODIO?
}

\author{
VICENTE A. SANJURJO RIVO
}


SUMARIO

1. EL HIPOTÉTICO DISCURSO RELIGIOSO DE ODIO POR RAZONES DE
GÉNERO, SEXO, ORIENTACIÓN O IDENTIDAD SEXUAL: ALGUNOS EJEMPLOS. 1.1. El discurso religioso de algunos ministros de culto de la confesión islámica acerca del rol de la mujer. 1.2. El mensaje religioso de algunas autoridades eclesiásticas católicas, o respaldado por ellas, sobre cuestiones de género, orientación e identidad sexual. 2. LA COBERTURA DEL MENSAJE RELIGIOSO CON RELEVANCIA PÚBLICA: LIBERTAD IDEOLÓGICA, RELIGIOSA Y LIBERTAD DE EXPRESIÓN. 2.1. La vertiente institucional de la libertad religiosa y la libertad de expresión: el derecho de las confesiones religiosas a divulgar y propagar su propio credo a través de redes y medios de comunicación social. 2.2. Libertad religiosa y libertad de expresión: relaciones y límites. 3. LIBERTAD RELIGIOSA Y DE EXPRESIÓN Y EXPRESIONES DE ODIO. 3.1. La ampliación de la conducta típica: de la provocación a la incitación directa e indirecta y a meros actos favorecedores y la difusión del mensaje de odio. 3.1.1. La idea provocadora como idea inequívocamente incitadora. 3.1.2. El debilitamiento del componente incitativo de la idea odiosa u hostil. 3.1.2.1. La expresión del mensaje de odio. 3.1.2.2. La difusión del mensaje de odio. 3.2. La creciente amplitud e indeterminación del discurso de odio y sus riesgos. 3.2.1. El aventurado tránsito de la acción intolerante a la idea intolerante. 3.2.2. El difícil encaje constitucional de esta configuración punitiva de las expresiones de odio. 


\title{
¿ES EL DISCURSO RELIGIOSO ODIOSO POR RAZONES DE GÉNERO, ORIENTACIÓN E IDENTIDAD SEXUAL UN DISCURSO DE ODIO?
}

\author{
VICENTE A. SANJURJO RIVO* \\ Profesor contratado doctor de derecho constitucional \\ 1. EL HIPOTÉTICO DISCURSO RELIGIOSO DE ODIO POR \\ RAZONES DE GÉNERO, SEXO, ORIENTACIÓN O \\ IDENTIDAD SEXUAL: ALGUNOS EJEMPLOS
}

Los denominados «discursos de odio» o «expresiones de odio» han experimentado un creciente protagonismo social y jurídico, que ha ido acompañado de un paulatino ensanchamiento de sus contornos. Prueba de esto último, entre nosotros, es la reforma del Código Penal (CP) de $2015^{1}$, por virtud de la cual se ampliaba el posible sujeto pasivo de los discursos de odio, añadiendo — en lo que aquí interesa— al sexo y a la orientación sexual, la identidad sexual y las razones de género.

El objeto de estudio del presente trabajo será el análisis acerca de si determinadas publicaciones respaldadas por el sello editorial de alguna confesión religiosa o las declaraciones y publicaciones de algunos ministros de culto de distintas confesiones, relacionadas todas ellas con distintos aspectos relativos a cuestiones de género o a la orientación o identidad sexual de las personas, podrían incluirse o no en la categoría de delito de odio tipificado en los artículos 510 y 510 bis del CP bajo el epígrafe «De

* Área de Derecho Constitucional, Facultad de Derecho, Universidad de Santiago de Compostela. Avda. Dr. Ángel Echeverri, s/n. Campus Vida. 15782-Santiago de Compostela. va.sanjurjo@usc.es ORCID ID: https://orcid.org/0000-0003-3087-967X

Modificación del Código Penal a través de la Ley Orgánica 1/2015, de 30 de marzo, que entró en vigor el 1 de julio de 2015. La reforma daba cumplimiento a la necesaria transposición de la Decisión Marco 2008/913/JAI, relativa a la lucha contra determinadas formas y manifestaciones de racismo y xenofobia mediante el Derecho Penal.

(C) UNED. Revista de Derecho Político 
los delitos cometidos con ocasión del ejercicio de los derechos fundamentales y de las libertades públicas garantizados por la Constitución» ${ }^{2}$.

\subsection{El discurso religioso de algunos ministros de culto de la confesión islámica acerca del rol de la mujer}

Mohamed Kamal Mostafa, imán de Fuengirola, publicó en 1997 el libro titulado «La mujer en el Islam» en el que, apoyándose únicamente, según el autor, en la sura 4 del Corán, en la Sunna — conjunto de preceptos que se atribuyen a Mahoma y a los primeros cuatro califas ortodoxos-y en los escritos de los sabios de los tres primeros siglos, se justificaba el maltrato físico infligido a la esposa por el marido y el rol de completa subordinación y discriminación de la mujer con relación al hombre en diferentes ámbitos, tales como la actividad laboral o las relaciones matrimoniales, entre otros ${ }^{3}$. El imán fue condenado como reo de un delito de provocación a la violencia contra grupos por razón de su sexo, si bien el juzgador estimó que, aun cuando la obra de autos promovía conductas discriminatorias contra las mujeres, no alcanzaba sin embargo a la provocación a la discriminación que exigía el tipo penal del artículo 510 CP en su redacción previa a la reforma de 2015, que era el de aplicación a este caso ${ }^{4}$.

El 14 de marzo de 2012 la Fiscalía Provincial de Barcelona (Servicio de delitos de odio y discriminación) interpuso, tras la apertura de las correspondientes diligencias de investigación penal (núm. 32/2012), una querella criminal contra Abdeslam Laaroussi, imán de Terrassa, en el Juzgado de Instrucción núm. 2 de la misma localidad, en el que, en el momento de escribir estas líneas, continúa aún en fase de instrucción. Los días 16 de diciembre de 2011 y 20 de enero de 2012, en ambos casos viernes y al mediodía, que es cuando se congrega un mayor número de fieles en la mezquita, el imán habría pronunciado sendos sermones, parcialmente transcritos en la querella de la fiscalía a partir de las grabaciones en soporte de audio registradas por agentes de Mossos d'Esquadra y tras su correspondiente traducción al castellano, en los que se contendrían expresiones que, a juicio de la fiscalía, podrían tener relevancia

2 Cabe advertir de la confusión por identificación entre los discursos del odio (arts. 510 y 510 bis CP) y los delitos de odio. Sin embargo, esta suerte de sinécdoque desconoce que los primeros — los discursos del odio - no son más que una parte o especie integrada en el todo o género que comprende los segundos - los delitos de odio-.

3 FERREIRO GALGUERA, J., (2004). «La libertad religiosa y la provocación a la violencia de género: el caso del imam de Fuengirola», Anuario da Facultade de Dereito da Universidade da Coruña, núm. 8, pp. 999-1003.

4 Sentencia del Juzgado de lo Penal núm. 3 de Barcelona, de 12 de enero de 2004. Una lectura crítica de esta sentencia, que excluye también la calificación jurídica de los hechos probados como delito de provocación a la violencia, puede seguirse en JERICÓ OJER, L., (2006). «El caso del Imán de Fuengirola: ¿auténtica comisión del delito de provocación a la violencia (art. 510.1 CP)?», Revista penal, núm. 18: 153-175. 
penal. En concreto, del contenido de las traducciones se pueden extraer expresiones que incitarían a la violencia física y psíquica contra la mujer y, por tanto, potencialmente vulneradoras de su derecho a la integridad física y moral (art. 15 CE). Asimismo, otras manifestaciones del imán vendrían a promover la discriminación contra la mujer, quebrantando el principio de igualdad (art. $14 \mathrm{CE}$ ), al auspiciar una posición de absoluta superioridad y control del hombre sobre la mujer. Todo ello aderezado además con una acerba crítica a la legislación española reconocedora de la igualdad entre hombres y mujeres, así como a los sistemas de protección de la mujer para el aseguramiento de sus derechos y contra la violencia de género. Por todo ello la fiscalía acusaba a Abdeslam Laaroussi de la posible comisión de un delito de provocación a la violencia y a la discriminación contra grupos por razón de su sexo (art. 510. 1 CP en su versión anterior a la reforma de 2015).

\subsection{El mensaje religioso de algunas autoridades eclesiásticas católicas, o respaldado por ellas, sobre cuestiones de género, orientación e identidad sexual}

A finales de 2013 la prensa se hizo eco de la publicación en español por la editorial Nuevo Inicio del Arzobispado de Granada de la obra titulada «Cásate y sé sumisa: experiencia radical para mujeres sin miedo», de la periodista italiana Costanza Miriano. En el libro se recogían afirmaciones, indicaciones, consejos, exhortaciones e incluso admoniciones dirigidas a la mujer casada, que comportaban un absoluto sometimiento de esta en sus relaciones conyugales, un ánimo de complacencia hacia el marido hasta extremos que podrían representar la anulación incluso de su voluntad ${ }^{5}$. Con todo, y ante la polémica suscitada por la publicación del libro, el Arzobispo de Granada, D. Francisco Javier Martínez Fernández, emitió un comunicado el 15 de noviembre de 2013 avalando el contenido de la obra en tanto que plenamente conforme con la doctrina de la Iglesia. Los grupos parlamentarios de IU, PSOE y PP, y también la por entonces ministra de Sanidad, solicitaron su retirada de la venta por considerar que algunos de sus contenidos podrían incurrir en apología de la violencia machista. El Consejo Municipal de la Mujer del Ayuntamiento de Granada, en decisión aprobada por unanimidad en Asamblea celebrada el 12 de noviembre de 2013, dio traslado de la obra a la Fiscalía de Granada instándole a que investigase el contenido del libro y las posibles consecuencias legales que del mismo podrían derivarse. En abril de 2014 la Sección de Violencia sobre la Mujer de la Fiscalía Provincial de Granada notificó el archivo de las diligencias informativas, al estimar que «aunque los párrafos recogidos, así como el propio título del libro pueden en algún caso y en el entorno de la sociedad actual igualitaria, ser poco acordes con el papel de la mujer en la sociedad actual, en ningún caso son merecedores de

\footnotetext{
5 Algunos de los fragmentos más polémicos de la obra pueden consultarse en http://www.eldiariohoy.com/2016/06/casate-y-se-sumisa-las-frases-mas-polemicas-del-libro-editado-por-el-arzobispado-de-granada.html [último acceso: febrero 2020].
} 
sanción penal con arreglo a la legislación vigente, [ya que] el texto del libro no constituye una apología de la violencia machista ni incita de manera directa a la discriminación, al odio o a la violencia».

El 25 de septiembre de 2014, el portal católico de internet Infovaticana publicaba en su sitio web un artículo del obispo de Alcalá de Henares, D. Juan Antonio Reig Pla, titulado «Llamar a las cosas por su nombre. Un verdadero reto para los católicos» ${ }^{6}$, escrito con motivo de la decisión del por entonces gobierno del PP de retirar la proyectada reforma de la Ley del aborto dirigida a modificar restrictivamente la Ley de plazos vigente. Además de al gobierno, el Sr. Reig Pla criticaba al Secretario General del PSOE, a la sazón principal partido de la oposición, por respaldar en la estación de Atocha de Madrid la campaña en favor del aborto promovida por grupos de mujeres que reivindicaban el derecho al aborto en un autodenominado «tren de la libertad». El obispo de Alcalá de Henares comparaba en su artículo ese supuesto «tren de la libertad» nada menos que con los trenes de Auschwitz, los trenes del holocausto nazi.

Por este motivo, en octubre de 2014, la asociación Tertulia Feminista Les Comadres presentó un escrito de querella contra el obispo de Alcalá de Henares y contra Infovaticana S.L., por un delito de injurias graves hechas con publicidad del artículo 208 y concordantes del CP, y un delito cometido con ocasión del ejercicio de los derechos fundamentales y de las libertades públicas reconocidos por la Constitución del artículo 510 y concordantes del CP, al contener el artículo, a juicio de los querellantes, un discurso del odio, con expresiones que incitan al odio y a la discriminación por razón de género contra todas las mujeres que defienden su derecho a interrumpir voluntariamente el embarazo.

El Juzgado de Instrucción núm. 2 de Alcalá de Henares, en Auto de 17 de diciembre de 2015, decidió no admitir la querella a trámite y archivar las actuaciones. Y motivó su decisión basándose en dos argumentos de distinta naturaleza. Uno, de carácter procesal, al considerar que ni la asociación querellante ni su presidenta estaban legitimadas para ejercer la acción penal o actuar como persona ofendida conforme a los artículos 215 y $510 \mathrm{CP}$, por no disponer de la condición de sujetos pasivos de los delitos imputados, al no ir dirigido directamente contra ellas el contenido del artículo (FJ 2). Y conforme al segundo argumento, de carácter sustantivo, el juzgador no aprecia la comisión de delito alguno en el contenido del artículo objeto de la querella. Por el contrario, estima que se trata de un artículo de opinión y que «la conducta que en la querella se imputa al querellado carece de antijuricidad material al estar amparada por la libertad de expresión y la libertad religiosa» (FJ 2).

Esta resolución del Juzgado de Instrucción núm. 2 de Alcalá de Henares de inadmisión de la querella interpuesta contra el Sr. Reig Pla fue confirmada por la sección

6 Disponible en https://infovaticana.com/blogs/firma-invitada/llamar-a-las-cosas-por-su-nombrepor-juan-antonio-reig-pla/ [último acceso: febrero 2020]. 
segunda de la Audiencia Provincial de Madrid, que desestimó el recurso de apelación interpuesto contra la misma.

Un par de años antes, concretamente el 6 de abril de 2012, con motivo de la liturgia de los Oficios de Viernes Santo, de nuevo el obispo de Alcalá de Henares, el Sr. Reig Pla, pronunciaba una homilía en alguno de cuyos pasajes denunciaba las penosas consecuencias morales que para las personas trae consigo la homosexualidad. Por el contexto - mensaje dirigido a fieles católicos congregados en torno a un acto estrictamente religioso - el discurso del obispo era eminentemente pastoral. Sin embargo, la ceremonia había sido retransmitida en directo por Televisión Española ${ }^{7}$, de manera que esas palabras obispales tuvieron una repercusión social, mediática y en redes sociales que ostensiblemente desbordaba el marco estrictamente religioso. Tanta repercusión que, diez días después, el Sr. Reig Pla concedió una entrevista al diario digital de información religiosa Religión en Libertad, en la que trataba de explicar in extenso el mensaje de su homilía del Viernes Santo. Entre otras cosas, y en lo que aquí ahora interesa, el prelado exponía que respecto a las personas con atracción sexual hacia el mismo sexo se debería evitar todo signo de discriminación injusta; que la particular inclinación de la persona con atracción sexual hacia el mismo sexo constituye una tendencia hacia un comportamiento intrínsecamente malo desde el punto de vista moral; y que, en fin, los actos sexuales entre personas del mismo sexo son intrínsecamente desordenados, contrarios a la Ley natural y no pueden recibir aprobación en ningún caso ${ }^{8}$.

Entre las múltiples reacciones que provocaron la homilía, primero, y las declaraciones a Religión en Libertad, después, hubo una denuncia presentada ante el Juzgado de Instrucción núm. 6 de Alcalá de Henares por la Asociación Preeminencia del Derecho por la supuesta comisión del delito previsto en el artículo 510 CP (en su redacción previa a la reforma de 2015). El titular del Juzgado resolverá, mediante auto de 10 de julio de 2012, que, tanto de las palabras pronunciadas por el Sr. Reig Pla con ocasión de la homilía del Viernes Santo como de sus declaraciones posteriores al medio Religión en Libertad, no se desprende la comisión de ninguno de los delitos tipificados en el artículo $510 \mathrm{CP}$, sino que, por el contrario, tales manifestaciones se encuentran amparadas por la libertad de expresión y la libertad religiosa y, en consecuencia, acordaba el sobreseimiento libre y el archivo de las actuaciones.

\footnotetext{
7 La retransmisión está disponible en http://www.rtve.es/alacarta/videos/semana-santa-en-rtve/ triduo-pascual-santos-oficios-06-04-12/1369592/ [último acceso: febrero 2020].

8 El contenido completo de la entrevista puede consultarse en https:/www.religionenlibertad. com/espana/21995/obispo-reig-pla-no-quiero-ofender-a-nadie-pero-no-renuncio.html [último acceso: febrero 2020]. La secuencia detallada de los hechos relacionados con las palabras de la homilía del Viernes Santo del obispo Reig Pla, y el eco y la réplica que tuvieron en los distintos medios de comunicación y en redes sociales puede seguirse en LÓPEZ-SIDRO LÓPEZ, Á, (2016). «La libertad de expresión de la jerarquía eclesiástica y el discurso del odio», Revista General de Derecho Canónico y Derecho Eclesiástico del Estado, núm. 42, pp. 3-6.
} 
Esta resolución del Juzgado de Instrucción de sobreseimiento de la causa fue recurrida por la entidad Soberanía de la Razón en recurso de apelación, que fue desestimado por la sección núm. 23 de la Audiencia Provincial de Madrid, mediante auto 487/14 de 30 de abril de 2014, al apreciar que el Sr. Reig Pla «se limitó a ejercer su libertad ideológica, religiosa y de opinión de forma pública» (FJ 2).

El 16 de mayo de 2016, con motivo de la clausura del curso del Instituto Juan Pablo II de estudios sobre la familia, el cardenal arzobispo de Valencia, D. Antonio Cañizares Llovera, pronunció una homilía en la capilla de la Sede de Santa Úrsula de la universidad Católica de Valencia, que tenía por título «En defensa y apoyo de la familia», en la que el pontífice hacía una encendida defensa de la familia tradicional y alertaba frente a lo que calificaba como amenazas de esta institución; entre otras, lo que denominó como «movimientos y acciones del imperio gay» y la insidiosa «ideología de género»". Días después, el cardenal arzobispo realizaba unas declaraciones durante la Solemnidad del Corpus, en las que exhortaba a los católicos a desobedecer las leyes de género. Como en otros casos similares, según se ha tenido ya oportunidad de comprobar, las palabras del Sr. Cañizares trascendieron el ámbito estrictamente religioso al tener una notable acogida en diferentes medios de comunicación, al punto que provocaron que se promoviese una declaración institucional de reprobación de las mismas — finalmente fallida - en el Pleno de las Cortes Valencianas; lo que, a su vez, originó, en una espiral vertiginosa, que el prelado desplegase una intensa actividad dirigida a explicar y justificar sus intervenciones pastorales ${ }^{10}$.

Al fin y a la postre, se presentaron dos denuncias contra el cardenal arzobispo de Valencia. Ambas denuncias se resolvieron en el Juzgado de Instrucción núm. 18 de Valencia, y el magistrado instructor juzgó que en las palabras del denunciado no se apreciaba una incitación o promoción directa o indirecta al odio, hostilidad o discriminación contra los homosexuales. Apoyándose en la jurisprudencia del Tribunal Constitucional, sostuvo que la libertad ideológica y la libertad de expresión no amparan ciertamente el menosprecio y el insulto contra personas o grupos, o la generación de sentimientos de hostilidad contra ellos; si bien — concluye el titular del Juzgado de Instrucción - que determinadas conductas queden extramuros de los contornos protegidos por las libertades ideológica y de expresión no implica indefectiblemente que constituyan ilícitos penales (FJ 7), por lo que declaraba el sobreseimiento provisional de las actuaciones.

Contra esta resolución se presentará recurso de apelación, que será resuelto mediante auto de la sección 4. ${ }^{\mathrm{a}}$ de la Audiencia Provincial de Valencia, de 12 de septiembre de 2016. Aprecia el Tribunal que ninguna de las expresiones o manifestaciones del cardenal arzobispo denunciadas encajaba en alguna de las conductas

9 El texto íntegro de la homilía puede aún consultarse en la web de la archidiócesis de Valencia: En defensa y apoyo de la familia. Disponible en http://archivalencia.org/contenido.php?a=6\&pad=6\&modulo $=37$ \&id $=13865$ \&pagina $=3$. [último acceso: febrero 2020 ].

10 Vid. LÓPEZ-SIDRO LÓPEZ, «La libertad de expresión de la jerarquía eclesiástica y el discurso del odio», pp. 17-18, cit. en nota núm. 8. 
tipificadas en el delito objeto de imputación, y que gozaban todas ellas de la cobertura de la libertad de expresión de ideas acerca de temas que integran el debate público. Por lo mismo, desestimaba el recurso de apelación interpuesto y confirmaba la resolución recurrida.

El 21 de marzo de 2016, pocos días después de ser aprobada por la asamblea de la comunidad autónoma de Madrid la Ley de Identidad y Expresión de Género e Igualdad Social y no Discriminación, el obispo de Alcalá de Henares, el Sr. Juan Antonio Reig, el de Getafe, el Sr. Joaquín M. ${ }^{a}$ López de Andújar y Cánovas del Castillo, y su obispo auxiliar, el Sr. José Rico Pavés, hicieron públicas unas reflexiones críticas $^{11}$ sobre la misma, a la que califican como Ley injusta e inicua y que, por lo tanto, a nadie obligaría en conciencia.

Como en los precedentes casos descritos, también en esta ocasión los reparos obispales a la Ley tuvieron gran eco y difusión y fueron fuente de polémica en los medios de comunicación y en las redes sociales. Incluso originaron, pocos días después, la presentación de una denuncia contra los tres obispos ante la Audiencia Provincial de Madrid, en nombre de la Confederación Española de Lesbianas, Gays, Bisexuales y Transexuales Colegas. Conforme a la denuncia, los denunciados, en su calidad de cargos eclesiásticos, y en el ejercicio de su derecho a la libertad de expresión, habrían elaborado y suscrito un documento crítico con la Ley de Identidad y Expresión de Género e Igualdad Social y no Discriminación, si bien, y a juicio de los demandantes, algunas expresiones contenidas en ese documento pastoral excederían el ámbito de protección dispensado por la libertad de expresión y encajarían en el tipo penal descrito en el artículo 510. 1 y 2 CP. En concreto, cuando los obispos aluden a que la Ley objeto de crítica vendría a regular graves atentados contra varios mandamientos de la Ley de Dios, estarían en realidad, según los demandantes, haciendo «una clara llamada al odio contra los que, en amparo de sus derechos, se acojan a las medidas que la Ley facilita para adecuar el género psicológico al género material». En suma, consideran los denunciantes que los obispos denunciados fomentaban el odio y la discriminación respecto de los transexuales, excluyéndolos, además del ámbito eclesiástico, también del ámbito social.

Lo que interesa ahora subrayar de los casos expuestos, por otra parte sin ánimo alguno de exhaustividad ${ }^{12}$, es que en todos ellos hay un mensaje religioso, transmitido oralmente o por escrito, por una autoridad o ministro de culto de la confesión islámica o católica, o avalado por ésta, en el que se adopta una posición, sustentada aparentemente en las doctrinas propias de cada confesión, sobre la condición de la mujer con relación al varón, o sobre determinados comportamientos de la mujer — por ejemplo

11 Su contenido íntegro está disponible en https://www.obispadoalcala.org/noticiasDEF2.php?subaction $=$ showfull\&id $=1458640800 \&$ archive $=\&$ start_from $=\& u c a t=1 \&$ [último acceso: febrero 2020 ].

12 Pueden seguirse otros supuestos similares, dentro y fuera de nuestras fronteras, en HERRERA CEBALLOS, E., (2018). «El discurso religioso contra la homosexualidad. Análisis desde la perspectiva de la libertad religiosa», Revista General de Derecho Canónico y Derecho Eclesiástico del Estado, núm. 47, pp. 3-6 y $13-23$.

(C) UNED. Revista de Derecho Politico

N. ${ }^{\circ} 112$, septiembre-diciembre 2021, págs. 175-214 
con respecto a su maternidad, como la interrupción voluntaria del embarazo-, que podría constituir, según determinados colectivos, una incitación al odio, la discriminación o la violencia contra un grupo por razón de su sexo o por razones de género. En otras ocasiones, como también se ha visto, esos mensajes religiosos denuncian la falta de cobertura moral que aquejaría el comportamiento y la tendencia sexual de lesbianas, gais, bisexuales, transexuales, transgénero, etc., lo que, para algunos, no serían otra cosa más que expresiones de odio que promueven la hostilidad, la discriminación o la violencia contra un grupo motivado por su orientación o identidad sexual.

Pero, además, y sobre esto tratamos a continuación, ese mensaje, indudablemente religioso en todos los casos, adquiere una difusión social y mediática que trasciende lo estrictamente religioso. El mensaje religioso se incorpora así al circuito del mercado de las ideas propio de una sociedad libre, abierta y democrática y, por consiguiente, será sometido a la valoración y crítica de grupos y personas ajenos a los que integran las confesiones religiosas, y a los que originariamente aquel mensaje va dirigido. Así pues, ese mensaje accede al debate público en el que intervienen, siguiendo el principio de pluralismo político (art. 1.1 CE), una multiplicidad de actores. Se convierte, en definitiva, en un mensaje con relevancia pública cuyo debate público y plural contribuye a la formación de la opinión pública sobre el tema o los temas objeto del mismo. Para entonces ese mensaje seguirá siendo ciertamente religioso, pero ya no será sólo un mensaje religioso, sino que aparecerá transmutado, por así decirlo, en un mensaje político-religioso. Y por ello algunas de las resoluciones judiciales reseñadas estimaban, como se ha visto, que con la difusión de esos mensajes no sólo se ejercía el derecho a la libertad religiosa, sino también a la libertad de expresión.

\section{LA COBERTURA DEL MENSAJE RELIGIOSO CON RELEVANCIA PÚBLICA: LIBERTAD IDEOLÓGICA, RELIGIOSA Y LIBERTAD DE EXPRESIÓN}

\subsection{La vertiente institucional de la libertad religiosa y la libertad de expresión: el derecho de las confesiones religiosas a divulgar y propagar su propio credo a través de redes y medios de comunicación social}

En realidad, en cualquiera de los supuestos antedichos los sujetos concernidos estarían ejerciendo, en última instancia, el derecho de libertad ideológica. Y es así porque en su dimensión positiva la libertad ideológica se proyecta siempre en otros derechos —aun cuando no cabría confundirla con ellos: STC 20/1990, de 15 de febrero, FJ 3, en relación con las libertades de expresión e información-, en este caso en los de libertad religiosa y de expresión. La libertad ideológica es el derecho de libertad matriz de los demás derechos de libertad y, en lo que ahora nos ocupa, también de las libertades religiosa y de expresión. 
Antes de entrar en consideraciones acerca de los delitos de odio y de si los supuestos antedichos constituyen o no, a nuestro juicio, expresiones de odio, conviene aproximarnos al contenido de los posibles derechos ejercidos en tales supuestos y a las relaciones entre ellos. Prima facie, los casos referidos recogerían expectativas de conducta que se cobijarían en el derecho de libertad religiosa. En todos ellos cabría apreciar la titularidad individual del derecho de cualquier persona a profesar las creencias religiosas que libremente elija y a manifestar libremente sus propias creencias religiosas. Pero además la libertad religiosa, concretamente en su vertiente positiva de manifestar la propia religión o creencias, es una libertad de titularidad no sólo individual, sino también comunitaria. Pues bien, en la medida en que en casi todos los casos señalados intervienen ministros de culto o miembros de la jerarquía eclesiástica, concurriría también en ellos el derecho de las Iglesias, Confesiones y Comunidades religiosas, una vez inscritas en el correspondiente Registro público, a divulgar y propagar su propio credo (arts. 5 y 2.2 LOLR).

Como acaece con la libertad ideológica, la libertad religiosa en su dimensión positiva se proyecta en otros derechos, aun cuando, con carácter general, no se confunde con ellos, y mantiene en principio ese posible haz de comportamientos que entran en conexión con el ejercicio de otros derechos fundamentales dentro del ámbito de protección de la libertad religiosa. Así sucede, por ejemplo, con los derechos de reunión, manifestación y asociación con fines religiosos [arts. 2.1 d); 2.2; y 6 LOLR]; el derecho a contraer matrimonio religioso [art. 2.1 b) LOLR]; el derecho de toda persona a impartir y recibir educación religiosa para sí y para los menores no emancipados e incapacitados bajo su dependencia [arts. 2.1 c) y 2.3 LOLR]; el derecho de fundación (art. 6.2 LOLR); o, en fin, el derecho a expresar y manifestar libremente las propias creencias o convicciones religiosas [art. 2.1 a) LOLR].

No obstante, con relación al último de los derechos mencionados —el derecho a expresar libremente las creencias religiosas de cada uno- cabría hacer alguna precisión adicional. Como antes se ha señalado, este derecho puede ejercerse individualmente o de forma comunitaria, que se identificaría, en esta segunda forma de ejercicio, con la libertad de culto (arts. 16.1 CE y 2.1 LOLR). Pero esta dimensión comunitaria del ejercicio de este derecho comprende también una vertiente institucional, que faculta a las iglesias, confesiones y comunidades religiosas a divulgar y propagar su propio credo (art. 2.2 LOLR). Las distintas confesiones religiosas pueden ejercer este derecho que les asiste no sólo con un fin de mero adoctrinamiento de sus fieles, sino también con una intención proselitista, a fin de ganar nuevos prosélitos para la confesión de que se trate en cada caso. Y al hacerlo resulta evidente que aquellas estarán ejerciendo su derecho de libertad religiosa en su dimensión comunitaria, al amparo de su legítima autonomía para la predicación de su doctrina.

Ahora bien, además de su incuestionable naturaleza religiosa, en las distintas confesiones religiosas concurre la condición de sujetos de la sociedad civil, de sujetos con dimensión y relevancia social —una y otra mayor o menor según los casos-y, 
como tales, productores de opinión pública ${ }^{13}$. En este sentido, los supuestos referidos en el apartado 1 de este trabajo constituyen una buena muestra de ello. Además, tal y como se ha podido constatar en esos mismos supuestos, o al menos en la mayoría de ellos, los sujetos involucrados transmitían el respectivo mensaje religioso a través de publicaciones o de medios de comunicación social institucionalizados. Llegados a este punto, cabría tal vez preguntarse por la naturaleza misma del mensaje o de los mensajes transmitidos. Que todos los descritos sean mensajes religiosos ofrece pocas dudas. Que esos mismos mensajes participen de naturaleza política es una cuestión que suscita, en cambio, más controversia. En cualquier caso, y como se ha podido comprobar en los casos aludidos, esos mensajes, sin duda de carácter religioso, generan un debate público que excede los márgenes de lo estrictamente religioso, pues se abre a toda la sociedad y participan del mismo no sólo ciudadanos más o menos anónimos a través de las redes sociales o distintos movimientos sociales más o menos concernidos por el objeto del debate, sino también actores políticos e incluso instituciones políticas que toman postura acerca de la polémica originada por el mensaje religioso en cuestión. Y ese debate abierto, plural, se desarrolla en términos esencialmente políticos. Visto desde esta perspectiva, difícilmente se puede concluir que el objeto de estos mensajes sea exclusivamente religioso. El mensaje trasciende su dimensión estrictamente religiosa en la medida en que origina un debate político-social, protagonizado por actores políticos y sociales que abordan el objeto del mensaje no en términos religiosos sino desde una orientación estrictamente política y hasta partidista.

Si se avanza en esta dirección podrá apreciarse, sin embargo, que la vertiente política de estos mensajes religiosos no trae causa únicamente de la naturaleza del debate que desencadenan, sino también del objeto mismo de tales mensajes. En ellos se ofrece, en última instancia, a partir de la doctrina religiosa propia de cada confesión, pautas o modelos de comportamiento social relacionados, al menos como se ha visto en los casos que nos ocupa, con el rol de la mujer, la elección de determinadas opciones afectivo-sexuales, modelos de unidad familiar etc., susceptibles de valoración político-social. Este punto de intersección entre lo político y lo religioso no debiera, en cualquier caso, provocar sorpresa o extrañeza. Al respecto, no debe perderse de vista que el bien jurídico protegido por la libertad ideológica y religiosa en su dimensión positiva es la protección de la libertad de pensamiento y de conciencia de los individuos, en definitiva, de su propia y particular cosmovisión, que entronca con el pluralismo político en cuanto valor superior del ordenamiento jurídico del Estado social y democrático de derecho (art. 1.1 CE).

En suma, el conjunto de las conductas anteriormente descritas no constituye únicamente el objeto de la libertad religiosa que, en lo relativo a la libre expresión de las propias creencias religiosas se proyecta, sin confundirse, en la libertad de expresión [art. 2.1 a) LOLR]; sino que tales conductas, por el carácter de los sujetos que emiten

13 Ibid, p. 32. 
el correspondiente mensaje, el medio empleado para hacerlo y/o por el contenido mismo del mensaje, integran también, tal y como por otra parte recogían algunas de las resoluciones judiciales señaladas, el objeto propio y autónomo de la libertad de expresión [art. 20.1 a) CE].

\subsection{Libertad religiosa y libertad de expresion: relaciones y límites}

Ambas libertades, como se ha visto, están en estrecha conexión. En unos casos, el derecho de libertad religiosa incluye expectativas de conducta que conectan con la libertad de expresión, aun sin confundirse con ella; mientras que, en otras ocasiones, determinados comportamientos que conforman el objeto del derecho de libertad religiosa, sin embargo, por las particulares circunstancias que en ellos concurren, lo desbordan y se subsumen también en el propio de la libertad de expresión.

Cualquiera de los comportamientos descritos, en cuanto ejercicio de los derechos de libertad religiosa y de expresión, esto es, en cuanto concreción en el espacio y en el tiempo de una determinada modalidad de conducta que integra el objeto de esos derechos fundamentales, no está sujeto a límite externo alguno. Si partimos de la premisa de que los artículos 53.1 y 81.1 CE no contienen una reserva genérica de limitación de los derechos fundamentales ${ }^{14}$, sino que únicamente establecen una reserva de Ley para la regulación del ejercicio y desarrollo de los derechos ${ }^{15}$; ni el artículo 16 CE (libertad ideológica y religiosa), ni el artículo 20.1 CE con relación a su apartado $4 .^{\circ}$, en el que se enuncian, sin ánimo exhaustivo (STC 187/1999, de 25 de octubre, FJ 3), algunos límites internos de la libertad de expresión e información (STC 6/1981, de 16 de marzo, FJ 4), contienen habilitación alguna al legislador para crear un límite en sentido propio o límite externo. Con relación a ellos, por tanto, el legislador —así como los jueces y tribunales y la administración— únicamente podrá concretar sus límites internos sin que pueda crear otros distintos ex novo ${ }^{16}$.

Así pues, por cuanto a sus límites se refiere, aparte el límite expreso del orden público previsto en el artículo 16.1 CE, tanto la libertad religiosa como la libertad de expresión vienen delimitadas por sus límites inmanentes, es decir, los que se derivan, de acuerdo con los principios de unidad constitucional y de igualdad de rango jurídico de las normas constitucionales, de la protección y garantía de otros derechos $\mathrm{u}$ otros bienes o intereses jurídicos constitucionalmente protegidos ${ }^{17}$.

14 BASTIDA FREIJEDO, F. J. et al., (2004). Teoría general de los derechos fundamentales en la Constitución española de 1978, 1. ${ }^{\text {a }}$ edic., Tecnos, pp. 132-133 y 139.

15 Entre otras, SSTC 58/1998, FJ 3; 292/2000, FJ 11; 14/2003, FJ 9.

16 BASTIDA FREIJEDO et al., Teoría general de los derechos fundamentales en la Constitución española de 1978, p. 133, cit. en nota núm. 14.

17 Igualdad de límites que, con relación a la libertad ideológica y a la libertad de expresión, se sostiene en la STC 214/1991, de 11 de noviembre, FJ 8. Sin embargo, en la STC 20/1990, de 15 de febrero, el TC estimaba que ambos derechos no estaban sujetos a idénticos límites, pues las restricciones a la libertad ideológica únicamente podrían fundamentarse excepcionalmente en un límite extremo, cual 
Bien es cierto que en esa operación de delimitación de los derechos fundamentales es preciso atender, además de a su dimensión subjetiva, también a la dimensión objetiva de las normas que los garantizan. Esta dimensión objetiva de los derechos fundamentales comporta un mandato de optimización a los poderes públicos, que deberán actualizar el contenido normativo de los derechos fundamentales de manera que permita su máximo desarrollo, lo cual, a su vez, tendrá efectos, entre otros, sobre el objeto de esos mismos derechos fundamentales, de modo que todas aquellas expectativas de conducta que en principio se correspondan con la definición abstracta contenida en la norma que contiene el derecho fundamental serán merecedoras de protección.

Esta fuerza expansiva de los derechos fundamentales no debe, por tanto, perderse de vista en esa operación de delimitación a la que antes nos referíamos. Sobre todo, si, como en el caso que nos ocupa, esa fuerza expansiva es potencialmente muy intensa. En efecto, tanto la libertad religiosa, por su conexión histórica y sistemática con la libertad ideológica, que conecta con valores como la libertad, la igualdad, el pluralismo político (art. 1.1 CE), la dignidad de la persona o el libre desarrollo de la personalidad (art. 10.1 CE), como la libertad de expresión, en cuanto instrumento indispensable para la existencia de una opinión pública libre, que, a su vez, es condición necesaria para el correcto funcionamiento del Estado democrático, encuentran en esta dimensión objetiva una fuerte vis expansiva de sus respectivos objetos, lo cual, a su vez, incide en esa tarea de delimitación de ambos derechos.

Cierto es, sin embargo, que el TEDH ha venido sosteniendo, en reiterada jurisprudencia $^{18}$, que cuando el ejercicio de la libertad de expresión tiene por objeto la manifestación, por cualquier medio, de opiniones acerca de la religión y sus dogmas, de manera que pudiesen dañar los sentimientos religiosos de terceros, podrá estar sujeto, al disponer los Estados de un más amplio margen de apreciación, a mayores restricciones respecto a cuando su ejercicio se conecta con la mera exposición de ideas políticas $^{19}$. Con ello, el TEDH discriminaba dos tipos de mensaje: uno específico, de contenido religioso, y otro genérico, de contenido político en sentido amplio, a los que atribuye un distinto nivel de protección.

es el mantenimiento del orden público protegido por la ley, ya que su reconocimiento en el artículo 16 CE gozaba de la «máxima amplitud». (FFJJ 3 y 4). No obstante, no estaríamos aquí, en realidad, ante una distinta delimitación de ambos derechos por sus límites, sino que más bien la dimensión objetiva de la libertad ideológica, que la propia sentencia reconoce al considerarla esencial "para la efectividad de los valores superiores y especialmente del pluralismo político» (FJ 3), incidiría en la mayor amplitud del objeto del derecho fundamental.

18 SSTEDH, Otto-Preminger Institut vs. Austria, de 24 de septiembre de 1994, §§ 47, 49 y 50; Wingrove vs, el Reino Unido, de 25 de noviembre de 1996, §§ 48, 58 y 64; I.A. vs. Turquía, de 13 de septiembre de 2005, §§ 24, 25.

19 BUSTOS GISBERT, R., (2005). «Los derechos de libre comunicación en una sociedad democrática (art. $10 \mathrm{CEDH)»,} \mathrm{Santolaya} \mathrm{Machetti,} \mathrm{P.} \mathrm{y} \mathrm{García} \mathrm{Roca,} \mathrm{F.J.,} \mathrm{(coord.),} \mathrm{La} \mathrm{Europa} \mathrm{de} \mathrm{los} \mathrm{derechos:}$ el Convenio Europeo de Derechos Humanos, Madrid: 1. a edic., Centro de Estudios Políticos y Constitucionales, p. 554. 
No obstante, el propio TEDH modificará esta línea argumental en su jurisprudencia posterior ${ }^{20}$, en la que vendría a sostener que, aun cuando los sentimientos religiosos de terceros constituían ciertamente un límite a la libertad de expresión, su capacidad limitadora, sin embargo, se reducía al mismo tiempo que lo hacía también el margen de apreciación de los Estados para restringir la libertad de expresión sobre la base de la supuesta ofensa de los sentimientos religiosos y, con ello, en consecuencia, se ampliaba su ámbito de protección.

En suma, el TEDH parece que termina por llevar a cabo una equiparación entre el mensaje de contenido religioso y el mensaje político o de cualquier otra naturale$\mathrm{za}^{21}$. El mensaje acerca de la religión, incluso aquel que puede zaherir los sentimientos religiosos de los que profesan una determinada fe, es, a fin de cuentas, mensaje y, por tanto, goza de la cobertura genérica de la libertad de expresión sin mayores particularidades a la hora de concretar o fijar sus límites. Mutatis mutandis, lo mismo cabría decir acerca de los mensajes religiosos, como aquellos a los que nos referíamos más arriba con cierto detalle, que, por las circunstancias que en ellos concurren y anteriormente descritas, exceden el ámbito del ejercicio de la libertad religiosa para encuadrarse también en el marco de protección de la libertad de expresión. Este tipo de mensajes no debieran, por tanto, estar sujetos a particulares límites en el ejercicio de la libertad de expresión o, dicho de otro modo, estarían sujetos a los mismos límites que, con carácter general, delimitan el derecho a la libertad de expresión. Así las cosas, pues, no cabría concretar límites distintos a la libertad de expresión dependiendo de la naturaleza del mensaje expresado.

\section{LIBERTAD RELIGIOSA Y DE EXPRESIÓN Y EXPRESIONES DE ODIO}

Admitido, aun cuando no sea del todo pacífico, que no procede la concreción de límites (internos) singulares cuando el contenido del mensaje es de naturaleza religiosa, bien porque en él se vierte una opinión acerca de la religión o bien porque expresa un juicio religioso sobre cualquier aspecto religioso o cualquier otro que exceda lo estrictamente religioso, la cuestión a abordar a continuación es si aquellas

20 SSTEDH, Giniewski vs. Francia, de 31 de enero de 2006, §§ 51-53 y 55; Aydin Tatlav vs. Turquía, de 2 de mayo de 2006, §§ 21, 22, 28, 30 y 31; Klein vs. Eslovaquia, de 31 de octubre de 2006, $\S \S 47,52$ y 54; Sekmadienis Ltd. vs. Lituania, de 30 de enero de 2018, $\$ 81$ y 83. No obstante, en un sentido parcialmente distinto, que evoca, al menos en cuanto a sus efectos, la anterior línea jurisprudencial, E.S. vs. Austria, de 25 de octubre de 2018. Sobre esta evolución jurisprudencial del TEDH, véase PRESNO LINERA, M. Á, (2019). «La libertad de expresión en la jurisprudencia del Tribunal Europeo de Derechos Humanos y del Tribunal Constitucional (Primera parte)», Cuadernos Digitales de Formación (CGPJ), Delitos de expresión en una sociedad democrática, núm. 40, pp. 25-29.

21 Equiparación que, por cierto, ya había efectuado el Tribunal Supremo de los Estados Unidos mucho tiempo atrás. Véase al respecto Cantwell v. Connecticut, 310 U.S. 296 (1940), y Joseph Burstyn, Inc. vs. Wilson, 343 U.S. 495 (1952).

(C) UNED. Revista de Derecho Politico

N. ${ }^{\circ} 112$, septiembre-diciembre 2021, págs. 175-214 
expresiones, declaraciones o publicaciones más arriba recogidas constituirían o no expresiones de odio subsumibles en el artículo 510 CP. Porque en el caso de que sí lo fuesen, y en cuanto el citado artículo resulta una concreción efectuada por el legislador de un límite a la libertad de expresión (y aquí también a la libertad religiosa), tales expresiones, en consecuencia, quedarían desprovistas de protección al quedar excluidas del objeto de ambas libertades.

Cierto es, como se ha visto, que salvo en alguna contada excepción, con carácter general los tribunales han venido apreciando de forma reiterada y concluyente que tales expresiones, orales o escritas, no encajan en el tipo penal descrito en el artículo 510 CP. Pero también lo es que casi todos los supuestos de hecho referidos se remontan a un lapso temporal previo a la reforma del Código Penal llevada a cabo mediante la Ley Orgánica 1/2015, de 30 de marzo (BOE núm. 77, de 31 de marzo de 2015) que, como veremos a continuación, procedió a una notable expansión del tipo previsto en el artículo $510 \mathrm{CP}$.

\subsection{La ampliación de la conducta típica: de la provocación a la incitación directa e indirecta y a meros actos favorecedores y la difusión del mensaje de odio}

\subsubsection{La idea provocadora como idea inequívocamente incitadora}

Como se acaba de señalar, la reforma del Código Penal de 2015 supuso una notable ampliación de varios elementos del tipo recogido en su artículo $510^{22}$. Sin embargo, nos interesa ahora llamar la atención, en particular, sobre la expansión de la conducta típica. El artículo $510 \mathrm{CP}$ en su redacción original incriminaba a los que «provocaren a la discriminación, al odio o a la violencia contra grupos o asociaciones» por motivos discriminatorios de naturaleza racista, sexual o por enfermedad. La literalidad del precepto suscitó la discusión doctrinal en torno a si la provocación recogida en el tipo debía interpretarse restrictivamente en los términos previstos en el

22 Se amplió el sujeto pasivo, que es común a todos los tipos delictivos regulados en el artículo 510 CP, al extenderlo, de conformidad con el artículo 1.1.a) de la Decisión Marco de 2008, no sólo a los grupos vulnerables o a una parte de los mismos, sino también a las personas físicas individualmente consideradas que pertenezcan a ellos. De otra parte, las conductas tipificadas en el artículo 510.1 CP exigen el dolo directo y, por tanto, el sujeto activo debe actuar movido por una serie de motivaciones discriminatorias que configuran el elemento subjetivo del tipo. Pues bien, con la reforma de 2015, y en lo que ahora aquí interesa, al sexo y a la orientación sexual, que ya figuraban en la anterior redacción entre las causas de discriminación que cualificaban subjetivamente la conducta típica, se añade la identidad sexual, a fin de extender la punición a supuestos de transfobia, y las razones de género, concebido este como el rol social que una sociedad determinada atribuye a hombres y mujeres, y que puede constituir un fundamento de acciones discriminatorias distintas del sexo biológico. 
artículo $18 \mathrm{CP}^{23}$, o bien, en cambio, admitía alguna otra interpretación alternativa y más amplia.

La provocación tipificada en el artículo $18 \mathrm{CP}$ es un acto preparatorio punible que exige una incitación directa, y con publicidad, a la comisión de un delito. En cuanto acto preparatorio comporta una manifestación en el mundo exterior de una resolución criminal, y el fundamento de su punición «estriba en la elevada probabilidad apreciada en las acciones preparatorias de conducir a una inminente incidencia efectiva sobre el bien jurídico protegido en los singulares tipos legales de delito» ${ }^{24}$. La dificultad que entrañaba interpretar la provocación del artículo 510 CP como acto preparatorio en los términos del artículo $18 \mathrm{CP}$ guardaba directa relación con que este último, como se acaba de señalar, exigía la incitación directa a la perpetración de un delito, mientras que el primero — el artículo $510 \mathrm{CP}$ — preveía la provocación a la comisión de actos que ciertamente pueden ser delictivos (la discriminación o la violencia), pero también a otros (el odio) que en modo alguno lo son. Odiar es un estado de ánimo, un sentimiento intenso de aversión o rechazo, pero no es un delito, ni siquiera un ilícito. De ahí que «difícilmente puede ser provocación la incitación directa al odio, ya que éste no es más que un estado de ánimo» ${ }^{25}$.

Por esta razón un sector de la doctrina sostuvo que la provocación prevista en el antiguo artículo 510 CP constituía un tipo autónomo y no un mero acto preparatorio de otros delitos ${ }^{26}$. Entre este sector doctrinal había un cierto consenso en que la provocación del artículo 510, tomando las características definidoras de la provocación como acto preparatorio del artículo $18 \mathrm{CP}$, debía traducirse en una incitación directa y pública — aun cuando la publicidad no estuviese expresamente prevista en el tipo- si bien no necesariamente a la comisión de un hecho propiamente delictivo $^{27}$. De este modo, y desde este enfoque doctrinal, podría sostenerse que la provocación descrita en el artículo $510 \mathrm{CP}$ constituye un supuesto de provocación sui generis, de manera que no está «sometida en su interpretación a un entendimiento del tipo ni en los términos — ni con los límites_ en que se configura la provocación como acto preparatorio en el artículo $18 »^{28}$. Y en buena medida esta orientación fue

23 «La provocación existe cuando directamente se incita por medio de la imprenta, la radiodifusión o cualquier otro medio de eficacia semejante, que facilite la publicidad, o ante una concurrencia de personas, a la perpetración de un delito» (art. 18.1 CP).

24 POlainO NAVARRETE, M., (1999). «Artículos 17 y 18», Cobo del Rosal, M., (dir.), Comentarios al Código Penal, t. I, Madrid: EDERSA, pp. 954-974.

25 COBO DEL ROSAL, M., (dir.) (1997). Curso de Derecho Penal español. Parte especial. T. II, Madrid: Marcial Pons, p. 688.

26 Así, por ejemplo, BENLLOCH PETIT, G., (2001). «El Derecho penal ante el conflicto político: reflexiones en torno a la relevancia penal de determinados fines, opiniones o motivos políticos o ideológicos y su legitimidad», Anuario de derecho penal y ciencias penales, 54, núm. 1, pp. 195-197.

27 Por todos, LAURENZO COPELLO, P., (1996). «La discriminación en el Código Penal de 1995», Estudios Penales y Criminológicos, vol. XIX, pp. 253-265.

28 LANDA GOROSTIZA, J. M., (1999). La intervención penal frente a la xenofobia: problemática general con especial referencia al 'delito de provocación' del artículo 510 del Código Penal, Bilbao: 1. edic., 
seguida por el TS al apreciar que la provocación del artículo 510 CP exigía una incitación directa, si bien el objeto de la misma consistiría en «la comisión de hechos mínimamente concretados de los que pueda predicarse la discriminación, el odio o la violencia ${ }^{29}$, o lo que es lo mismo, en hechos que pudieran no ser constitutivos de delito en sentido estricto.

Ahora bien, tanto si se concebía el tipo previsto en el antiguo artículo $510 \mathrm{CP}$ como un acto preparatorio o como un tipo autónomo, en ambos casos el fundamento de la punición es muy similar. Pues tanto en un caso como en el otro la justificación de la sanción descansaría en la puesta en peligro o en el inminente riesgo de lesión de determinados bienes jurídicos merecedores de protección. Y es entonces cuando podrían surgir algunas dudas acerca de la configuración del artículo 510 CP como tipo autónomo que describe como hecho típico una provocación singular a la comisión de unos hechos que podrían ser antijurídicos o no.

Si consideramos que los bienes jurídicos protegidos por este tipo penal son la igualdad y la seguridad de los grupos, es fácil deducir el fundamento de la sanción del hecho típico cuando efectivamente supone una puesta en peligro abstracto de la igualdad (incitación directa a la discriminación) o de la seguridad (incitación directa a la violencia) de esos mismos grupos ${ }^{30}$. En cambio, no resultaría tan fácil encontrar el fundamento punitivo en el caso de la incitación al odio (o a la hostilidad introducida por la reforma de 2015), ya que en este caso se estaría sancionando la posible generación de un sentimiento colectivo de antipatía o aversión por móviles discriminatorios contra determinados grupos que, a su vez, en un futuro más o menos próximo, podría desencadenar actuaciones que por sí mismas pudiesen poner en riesgo esos bienes, o bien que incitasen a terceros a comportamientos discriminatorios o violentos contra esos mismos grupos. Así pues, no estaríamos en este caso ante un inminente riesgo de lesión de los bienes jurídicos objeto de protección, sino más bien se estaría penalizando, no ya la efectiva puesta en peligro abstracto de la igualdad o la seguridad de los grupos sujetos pasivos del delito, sino el peligro potencial o hipotético de peligro abstracto para la igualdad o la seguridad de esos grupos, con el consiguiente adelantamiento desmedido de la barrera punitiva y la posible injerencia en el núcleo esencial de las libertades de expresión, ideológica y religiosa (arts. 20 y $16 \mathrm{CE}$ ).

En cambio, desde otra óptica, se considera que el bien jurídico protegido en el delito de expresiones de odio es la tutela de la seguridad existencial de determinados grupos vulnerables ${ }^{31}$. Vendría a corroborar esta hipótesis una interpretación siste-

Universidad del País Vasco, Servicio Editorial = Euskal Herriko Unibertsitatea, Argitalpen Zerbitzua, p. 224.

STS núm. 259/2011, de 12 de abril, FD 1.².

30 PORTILlA CONTRERAS, G., (2016). «La represión penal del 'discurso del odio'», Álvarez García, F.J., (dir.), Manjón-Cabeza Olmeda, A. y Ventura Püschel, A., (coord.), Tratado de derecho penal español: Parte especial. IV. Delitos contra la Constitución, Valencia: 1 edic., Tirant lo Blanch, pp. 364-365.

31 LANDA GOROSTIZA, J. M., (2018). Los delitos de odio, Valencia: Tirant lo blanch, pp.57-63. 
mática del tipo penal, que se inserta en el título relativo a los Delitos contra la Constitución y en el capítulo que comprende los delitos relativos al ejercicio de los derechos fundamentales y libertades públicas. Así pues, con la tipificación de las expresiones que incitan públicamente al odio se perseguiría dar protección a determinados colectivos que podrían ver dificultado o suprimido el ejercicio de determinados derechos fundamentales. Con las expresiones de odio, en definitiva, se alentaría la creación de, por así decirlo porque en sí mismo constituye una contradictio in terminis, diferentes niveles de ciudadanía: así por ejemplo, hombres frente a mujeres, heterosexuales frente a homosexuales, transexuales, etc. El objetivo último del mensaje de odio sería no tanto, aunque también, menoscabar la igualdad o la dignidad de los miembros del grupo destinatarios del mensaje, cuanto minar las bases de seguridad del colectivo. Los integrantes del grupo diana, en la terminología acuñada por Landa Gorostiza ${ }^{32}$, intersubjetivamente llegarían probablemente a percibir que, en el contexto en el que se emite el discurso de odio, podrían de forma plausible ver seriamente comprometido el ejercicio individual de determinados derechos, que en los casos más extremos podría afectar al derecho a la vida o a la integridad física, pero también al ejercicio de otros derechos como la libertad religiosa, la expresión de la propia identidad, derechos de participación política, etc.

Ahora bien, desde esta interpretación del bien jurídico protegido, no cualquier incitación al odio contra un determinado grupo será típicamente relevante, sino únicamente cuando ese mensaje de odio sea eficaz y haga crisis, es decir, cuando se inserte en un contexto social crítico, en un caldo de cultivo que lo haga particularmente peligroso y dañino para la convivencia. Una vez más, sin embargo, al hacer depender ese juicio de peligro ex ante de determinados contextos o climas sociales críticos - ya de por sí de difícil discernimiento en términos de seguridad jurídica salvo que pudiesen reconducirse a alguna situación excepcional objetiva como las previstas en el artículo 116 CE (estados de alarma, de excepción y de sitio)— el riesgo de una posible restricción desproporcionada de las libertades ideológicas, de creencias o de expresión resulta evidente.

En cualquier caso, ya se siguiese una interpretación más restrictiva del tipo previsto en el antiguo artículo $510 \mathrm{CP}$, como simple acto preparatorio, u otra más amplia que lo concebía como tipo autónomo, había un cierto acuerdo en que la provocación tipificada en dicho precepto se identificaba con una incitación directa a la discriminación, a la violencia y, en su caso, también al odio. Y ello, en buena medida, explicaría también que de los casos reseñados en el apartado 1 - la mayoría de ellos referidos a hechos acaecidos con anterioridad a la reforma de 2015 - sólo en uno de ellos (el del imán de Fuengirola) se hubiese finalmente impuesto una condena fundada en el artículo $510 \mathrm{CP}$.

32 LANDA GOROSTIZA, J. M., (2012). «Incitación al odio: evolución jurisprudencial (19952011) del art. 510 CP y propuesta de 'lege lata'», Revista de derecho penal y criminología, núm. 7, p. 303. 


\subsection{El debilitamiento del componente incitativo de la idea odiosa u hostil}

\subsubsection{La expresión del mensaje de odio}

Será la STC 235/2007, de 7 de noviembre, la que comience a decantar la orientación de este debate doctrinal y a abrir la senda que conducirá a la reforma de 2015 . En ella el TC enjuiciaba la constitucionalidad del ya desaparecido artículo 607.2 CP que castigaba la difusión, por cualquier medio, de ideas o doctrinas tendentes a negar o justificar el delito de genocidio. Y lo declara parcialmente inconstitucional al resolver que la sola negación del genocidio constituye una mera transmisión de ideas y su criminalización, en consecuencia, supone una vulneración del derecho a la libertad de expresión (FFJJ 6 y 8). En cambio, declara que no es inconstitucional tipificar como delito la difusión de ideas o doctrinas tendentes a justificar el genocidio siempre que el precepto controvertido sea interpretado conforme a los criterios fijados en la sentencia. En este sentido, el TC, tal vez en una interpretación un tanto sesgada de la jurisprudencia del $\mathrm{TEDH}^{33}$, identifica el discurso del odio como límite a la libertad de expresión con aquellas expresiones que supongan «una incitación directa a la violencia contra los ciudadanos en general o contra determinadas razas o creencias en particular» (FFJJ 5 y 8 ) (cursivas nuestras).

Sin embargo, al fundamentar la constitucionalidad del delito de justificación del genocidio, entiende el Tribunal que en tal justificación anida un juicio de valor sobre los hechos o su antijuricidad que puede operar como una incitación indirecta a su comisión. De igual modo, se salvaría a su vez la posible tacha de inconstitucionalidad del precepto cuando «con la conducta consistente en presentar como justo el delito de genocidio se busque alguna suerte de provocación al odio hacia determinados en (sic) grupos definidos mediante la referencia a su color, raza, religión u origen nacional o étnico, de tal manera que represente un peligro cierto de generar un clima de violencia y hostilidad que puede concretarse en actos específicos de discriminación» (FJ 9). Y en lo que ahora interesa llamar la atención, el Alto Tribunal parece zanjar definitivamente aquella polémica doctrinal desvinculando el término provocación de la incitación directa tal y como aparece recogido en el artículo 18 CP. De este modo, el TC estima justificada la tipificación o incriminación de «conductas que aunque sea de forma indirecta supongan una provocación al genocidio». En la misma línea argumental, sostiene el Tribunal que «[t]an íntima vinculación con el valor nuclear de cualquier sistema jurídico basado en el respeto a los derechos de la persona permite al legislador perseguir en este delito modalidades de provocación, incluso indirecta, que en otro caso podrían quedar fuera del ámbito del reproche penal», de suerte que será «constitucionalmente legítimo castigar penalmente conductas que, aun cuando no resulten claramente idóneas para incitar directamente a la comisión de delitos

33 LANDA GOROSTIZA, Los delitos de odio, p. 54 y remisión efectuada en esta misma página en nota núm. 95, cit. en nota núm. 31. 
contra el derecho de gentes como el genocidio, sí suponen una incitación indirecta a la misma o provocan de modo mediato a la discriminación, al odio o a la violencia, que es precisamente lo que permite en términos constitucionales el establecimiento del tipo de la justificación pública del genocidio (art. 607.2 CP)» (FJ 9). En definitiva, el TC atribuye al tipo previsto en el antiguo art. 607.2 CP (y por extensión también al recogido en el art. 510 CP previo a la reforma de 2015) un ámbito punible propio sustentado en una modalidad específica de incitación al delito distinta y diferenciada respecto a la modalidad delictiva definida con carácter general en el art. 18 CP y a la provocación directa al delito de genocidio (art. 615 CP), lo que, además, explicaría su penalidad diferenciada, por su levedad, con relación a esta última —la provocación directa a la comisión del delito de genocidio- que preveía una pena inferior en uno o dos grados al delito provocado (FJ 9).

Recogiendo reiterada doctrina del $\mathrm{TEDH}^{34}$, el TC reconoce que la libertad de expresión protege también aquellas ideas que contrarían, chocan o inquietan al Estado o a una parte cualquiera de la población (FJ 4). Y al mismo tiempo advierte que el denominado discurso del odio quedaría extramuros del ámbito de protección de la libertad de expresión en la medida en que lesiona efectivamente derechos o bienes de relevancia constitucional (FJ 4). El problema estriba en que, al ampliar, como hace el TC en esta sentencia, los márgenes de la provocación al odio por la vía de las incitaciones indirectas y de la generación potencial de climas sociales de hostilidad contra determinados grupos, se corre el riesgo de ir reduciendo paralelamente el objeto de protección de la libertad de expresión. Expansión y retracción respectivamente que, de llevarse al extremo, podría conducir, de un lado, a que, por ejemplo, toda opinión racista o xenófoba termine por equiparse a un insulto y, por tanto, se excluya de la cobertura de las libertades de expresión y religiosa, o bien a que, de otro, toda opinión racista o xenófoba, toda opinión hostil, se convierta en una incitación a actos lesivos o en una generación de situaciones o ambientes potencialmente lesivos, de manera que, «[a] la postre, se legitima el castigo de la mera transmisión de ideas execrables» ${ }^{35}$. Cierto es que esta deriva peligrosa podría sortearse si se trazase una línea que deslinde entre «la ofensa a una etnia, la incitación o provocación al genocidio, a la discriminación, al odio racial y a la violencia — que en ningún caso pueden gozar de la protección constitucional a la libertad ideológica y a la libertad de expresión - y, de otro lado, la expresión de convicciones contrarias a determinados valores en la formulación constitucionalmente acogida» ${ }^{36}$. Sin embargo, el trazo de esa línea, firme y definido en la teoría, seguramente se volverá vacilante y difuso

34 Entre otras, SSTEDH Handyside c. Reino Unido, de 7 de diciembre de 1976, § 49, y De Haes y Gijsels c. Bélgica, de 24 de febrero de 1997, § 46.

35 ALCÁCER GUIRAO, R., (2018). «Opiniones constitucionales», Indret: Revista para el Análisis del Derecho, núm. 1, p. 21.

36 ROLLNERT LIERN, G., (2008). «Revisionismo histórico y racismo en la jurisprudencia constitucional: los límites de la libertad de expresión (a propósito de la STC 235/2007)», Revista de derecho político, núm. 73, p. 141. 
en la realidad práctica, lo que inevitablemente se traducirá en un amplio margen de apreciación para los jueces y tribunales a la hora de determinar en qué lado de la línea cae el comportamiento enjuiciado, con el consiguiente menoscabo del principio de seguridad jurídica.

Por otra parte, cierto es, como señala Portilla Contreras al cuestionar la opción legislativa seguida en la reforma del CP de 2015, que la Decisión Marco 2008/913/ JAI del Consejo, de 28 de noviembre de 2008, relativa a la lucha contra determinadas formas y manifestaciones de racismo y xenofobia mediante el Derecho penal (DOUE, núm. 328, de 6 de diciembre de 2008) «[n]o sanciona los actos de promoción, fomento e incitación indirecta y tampoco los supuestos de producción, elaboración, ni los de difusión o reparto que no signifiquen una incitación directa» ${ }^{37}$ y que, en cambio, sí acabaría recogiendo el tipo previsto en el artículo $510 \mathrm{CP}$ tras la reforma de 2015; pero también lo es que la DM exigía la sanción de la apología pública, la negación o la trivialización flagrante de los crímenes de genocidio, contra la humanidad y crímenes de guerra, siempre que esas conductas pudiesen incitar a la violencia o al odio [art.1.1 c) y d) DM 2008/913/JAI]. Con ello la DM abría las puertas para incluir en la conducta típica las incitaciones indirectas y aquellos comportamientos con capacidad objetiva ex ante para generar peligros potenciales de que terceros ejerciesen la violencia o actos de odio, lo cual, en nuestro caso, y a la vista de la por entonces reciente jurisprudencia del TC sentada en la sentencia recién comentada, suponía no restringir necesariamente la conducta típica a la incitación directa y, desde luego, desvincular ésta del concepto de provocación en los términos previstos en el art. 18 del CP.

El legislador, en fin, siguiendo la estela de esta ampliación de la conducta típica, hacía suyas las tesis de la Fiscalía General del Estado y las acabará incorporando sin reservas en la reforma de 2015. En efecto, en la Memora de la Fiscalía de 2012 se recogían algunas propuestas de modificación del tipo de provocación a la discriminación (antiguo art. $510 \mathrm{CP}$ ). Entre otras, a fin justamente de superar la discusión doctrinal acerca de si la conducta debía enmarcarse o no en la provocación en sentido técnico (art. $18 \mathrm{CP}$ ) y evitar interpretaciones excesivamente restrictivas, se sugiere introducir como verbos típicos, en lugar de provocaren, los de incitaren, promovieren y difundieren, los cuales finalmente aparecerán recogidos en la relación de verbos típicos incorporados al tenor literal del nuevo artículo reformado ${ }^{38}$.

De este modo, con la sustitución del verbo típico provocar del antiguo artículo $510 \mathrm{CP}$ por los de fomentar, promover e incitar directa o indirectamente introducidos por la reforma penal de 2015 se zanjaba definitivamente el debate doctrinal y jurisprudencial acerca de si la provocación al odio, a la discriminación o a la violencia

37 PORTILLA CONTRERAS, «La represión penal del 'discurso del odio'», p. 358, cit. en nota núm. 30 .

38 Vid. Memoria de la Fiscalía General del Estado, Madrid, 2012, pp. 1259 y ss. 
debía o no vincularse al artículo 18 CP y, con ello, el legislador ampliaba decididamente la conducta típica.

La incitación indirecta, a la que como ya se ha señalado abrió paso la STC 235/2007, comporta que el mensaje incitador punible, el contenido de injusto, no se reduce únicamente a aquel que se expresa en unos términos inequívocos o incluso groseros, dolosamente dirigido a implicar a terceros en la realización de actos discriminatorios o violentos contra determinados grupos vulnerables, sino que incluiría también aquel otro menos evidente, más sutil, incluso supeditado a su puesta en escena o al contexto social en que se emite, ampliando así, una vez más, los márgenes de la interpretación y reduciendo los de la seguridad jurídica.

Por otra parte, con la adición de los verbos típicos de fomentar y promover, por lo demás no recogidos en la Decisión Marco 2008/913/JAI, el legislador ampliaba la conducta típica a actos de favorecimiento, o de favorecimiento del favorecimiento que, según un sector de la doctrina, en realidad solo debieran ser punibles «cuando se conviertan en supuestos de participación en delitos discriminatorios o violentos o actos preparatorios de los mismos, [pues] de otra manera estarían incluidos en la incitación indirecta o serían irrelevantes para el Derecho penal» ${ }^{39}$.

Bien es cierto, no obstante, que desde una interpretación conjunta o global del artículo $510 \mathrm{CP}$ podría sostenerse que los verbos típicos incitar, fomentar o promover condensan en realidad el contenido de injusto y describen el hecho típico abarcándolo en sus diversas manifestaciones: discursos destinados a implicar (incitar) a sectores de la sociedad, o a mover o ganar voluntades (promover y fomentar) a fin de menoscabar la pacífica convivencia entre grupos y colectivos con posible afectación de sus derechos fundamentales ${ }^{40}$.

De cualquier modo, y como se señalaba con anterioridad, la conducta típica resulta evidentemente ampliada con la reforma: de la provocación se da paso a la incitación directa o indirecta y a actos de fomento y promoción, y al objeto de la incitación —el odio, la discriminación o la violencia — se le añade la hostilidad. La cuestión no es ni mucho menos banal, y podría acarrear un cambio de orientación en la línea jurisprudencial descrita hasta el momento y afectar, en consecuencia, a aquellos supuestos relacionados más arriba aún pendientes de resolución judicial, cuyos hechos se remontan a un momento posterior al 1 de julio de 2015, fecha de la entrada en vigor de la nueva regulación relativa a los discursos de odio.

Bien es cierto, no obstante, que no parece apreciarse este giro jurisprudencial, al menos de momento y en los casos que guardan alguna relación con el objeto de este trabajo. Una buena muestra de ello podría ser el auto de la Audiencia Provincial de Murcia 736/2017, de 8 de septiembre, que resolvió un recurso de apelación presentado por la asociación «No te prives» contra el auto de 20 de marzo de 2017 dictado

39 PORTILLA CONTRERAS, «La represión penal del 'discurso del odio'», p. 365, cit. en nota núm. 30.

40 LANDA GOROSTIZA, Los delitos de odio, pp. 67 68, cit. en nota núm. 31. 
por el Juzgado de Instrucción núm. 4 de Murcia, que inadmitía a trámite la querella interpuesta por la asociación antedicha por la posible comisión de un delito de injurias y/o delito de odio, a causa de unas manifestaciones realizadas con motivo de la apertura del curso universitario de la Universidad Católica San Antonio de Murcia (UCAM) el 11 de noviembre de 2015, recogidas por diversos medios informativos, en las que se afirmó que «el mal llamado matrimonio homosexual es una abominación a ojos de Dios», y decretaba como consecuencia de la inadmisión el sobreseimiento libre de la causa. La Audiencia desestimó el recurso de apelación, confirmando íntegramente el auto del Juzgado de Instrucción, lo que parece suscitar alguna duda a algún sector doctrinal ${ }^{41}$. Y posiblemente esté justificada la misma, porque lo cierto es que de la lectura del auto de la Audiencia parece desprenderse que la estructura de la conducta típica que utiliza, y aun cuando reproduce en su integridad la literalidad del artículo 510 CP en su nueva redacción, se asemeja más a la que contenía el tipo previo a la reforma.

En efecto, la Sala de la Audiencia, siguiendo el criterio defendido por el Ministerio Fiscal en su informe de 12 de junio de 2017, sostiene que la conducta típica del artículo 510.1 CP supone que «la provocación (sic) debe dirigirse a la discriminación o a la violencia que ha de entenderse en sentido estricto destinada a la realización de determinados delitos contra grupos o asociaciones» por motivos discriminatorios; y «[a]simismo cuando la provocación (sic) va dirigida al odio ha de interpretarse en un sentido restrictivo como actitud de rechazo irracional concretada, en todo caso, mediante una incitación directa siempre y cuando se pretenda materializar una conducta constitutiva de delito» (RJ 3; cursivas nuestras). De ello parece desprenderse o inferirse que el Tribunal lleva a cabo un juicio ex ante de peligro abstracto sobre una conducta típica que evoca la configuración que esta tenía en la redacción del tipo del artículo 510.1 CP previo a la reforma, y no a la que resultó, según hemos visto, como consecuencia de su modificación por el legislador tras la reforma de 2015 .

\subsubsection{La difusión del mensaje de odio}

Esta expansión de la conducta típica se acentúa si acaso más con la redacción del nuevo artículo $510.1 \mathrm{~b}$ ) que incrimina a quienes «produzcan, elaboren, posean con la finalidad de distribuir, faciliten a terceras personas el acceso, distribuyan, difundan o vendan escritos o cualquier otra clase de material o soportes que por su contenido sean idóneos para fomentar, promover, o incitar directa o indirectamente al odio, hostilidad, discriminación o violencia» contra un grupo vulnerable o contra una persona determinada por razón de su pertenencia al mismo, y por los mismos móviles discriminatorios relacionados en el artículo 510.1 a).

41 DE VICENTE MARTínEZ, R., (2018). El discurso del odio. Análisis del artículo 510 del Código Penal, Valencia: 1. ${ }^{a}$ edic., Tirant lo Blanch, pp. 130-131. 
El tipo descrito prevé conductas y comportamientos que son previos a los recogidos en el artículo 510.1 a) y a los que, sin embargo, se le asocia la misma pena. Por ello, según ha expresado buena parte de la doctrina ${ }^{42}$, además de suponer en algunos casos un adelantamiento desmesurado de la barrera punitiva que entraría en colisión con el principio de lesividad, se conculcaría también el principio de proporcionalidad de las penas. En este caso no se está tipificando, como sucede en el artículo 510.1 a) $\mathrm{CP}$, la incitación, el fomento o promoción al odio, hostilidad, discriminación o violencia, sino la elaboración, distribución y difusión o venta de una serie de materiales que, a su vez, resulten idóneos para desencadenar esa incitación o fomento o promoción de odio, hostilidad, discriminación o violencia contra determinados grupos ${ }^{43}$. No se trataría, por tanto, de efectuar como en el apartado a) del art. 510.1 un juicio acerca de la efectiva puesta en peligro abstracto o, en el caso de la incitación al odio o a la hostilidad, del peligro potencial o hipotético de peligro abstracto para los bienes jurídicos merecedores de protección por el tipo penal, sino que el órgano jurisdiccional deberá realizar en el caso del artículo 510.1 b) un control de idoneidad de esos materiales acerca de su capacidad potencial para poner en peligro abstracto (en el caso de que inciten a la violencia o a la discriminación) o de su capacidad potencial para generar el peligro del peligro abstracto de lesión de los bienes jurídicos en juego (en caso de que inciten al odio o a la hostilidad $)^{44}$.

42 Véase, por ejemplo, ROIG TORRES, M., (2015). «Los delitos de racismo y discriminación (arts. 510, 510 BIS, 511 y 512)», González Cussac, J.L., (dir.), Matallín Evangelio, Á y Górriz Royo, E., (coord.), Comentarios a la reforma del Código Penal de 2015, Valencia: 1. a edic., Tirant lo Blanch, p. 1212; ALASTUEY DOBÓN, M. C., (2014). «La reforma de los delitos de provocación al odio y justificación del genocidio en el Proyecto de Ley de 2013: consideraciones críticas (1)», Diario La Ley, núm. 8245, p. 13; TAPIA BALLESTEROS, P., (2015). «Artículo 510», Gómez Tomillo, M. y Javato Martín, A.M., (dir.), Comentarios prácticos al Código penal, t. VI, Pamplona: 1. a edic., Aranzadi Thomson Reuters, p. 187, o DE VICENTE MARTÍNEZ, El discurso del odio. Análisis del artículo 510 del Código Penal, pp. 145-146, cit. en nota núm. 41.

43 TERUEL LOZANO, G. M., (2015). «La libertad de expresión frente a los delitos de negacionismo y de provocación al odio y a la violencia: sombras sin luces en la reforma del código penal», Indret: Revista para el Análisis del Derecho, núm. 4, pp. 33-34. Landa Gorostiza, sin embargo, en la construcción que efectúa del delito del discurso de odio, concibe las distintas acciones típicas previstas en el artículo 510.1.b) como partes de un todo, partes consolidadas de lo que denomina «cadena de difusión del discurso del odio». Pues bien, en la fase dentro de esta cadena de difusión que se corresponde con la distribución, difusión o venta, podría haber un despliegue efectivo de los mensajes, es decir, podrían constituir conductas materialmente incitadoras, de manera que dentro del tipo convivirían conductas preparatorias de la incitación y conductas efectivas de incitación, y en este segundo caso estaríamos ante una modalidad específica de comisión de la conducta típica del artículo 510.1 a), en la que la incitación al odio o a la violencia se lleva a cabo, no de palabra, sino mediante escritos o soporte equivalente (LANDA GOROSTIZA, Los delitos de odio, pp. 74-75, cit. en nota núm. 31).

44 De aplicar este juicio de idoneidad referido, además, a categorías tan amplias y difusas como el mero fomento o la promoción o las incitaciones directas o indirectas, el Tribunal Supremo habría podido resolver en sentido distinto al que lo hizo en el caso de la Librería Kalki, en el que absolvió, tras casar y anular la sentencia dictada por la Audiencia Provincial de Barcelona, a los acusados como criminalmente responsables de los delitos de difusión de ideas genocidas (art. 607.2 CP) y de un delito cometido con ocasión del ejercicio de los Derechos fundamentales y de las Libertades públicas garantizados por

(C) UNED. Revista de Derecho Politico

N. ${ }^{\circ} 112$, septiembre-diciembre 2021, págs. 175-214 
El delito se consuma con la mera posesión para difundir, con la distribución, o con la difusión y venta de escritos o cualquier otra clase de material o soporte, siempre que estos sean idóneos para favorecer o incitar directa o indirectamente al odio, hostilidad, discriminación o violencia contra un grupo diana por motivaciones discriminatorias. No es necesario, por tanto, para incurrir en responsabilidad penal, que quien distribuya o difunda esos materiales potencialmente incitadores manifieste expresamente su identificación con el mensaje divulgado, sino que bastará su nuda difusión, aunque no haya adhesión ni se asuma el contenido difundido.

Así pues, la capacidad de expansión de las posibles conductas típicas de este precepto es extraordinaria. Si dirigimos ahora de nuevo la atención a los casos señalados al inicio de este trabajo, la condena del imán de Fuengirola por un delito de provocación a la violencia contra las mujeres por el contenido del libro de su autoría titulado «La mujer en el Islam», debiera haber ido acompañada, de acuerdo con la redacción del nuevo artículo 510.1 b), de otra condena por su publicación a la librería catalana la Casa del Libro Árabe. De igual modo, y por seguir con este ejercicio cabalístico, en el supuesto de que, conforme a la nueva regulación, algunos de esos mismos hechos anteriormente pormenorizados hubiesen sido objeto de condena, esta muy probablemente no se habría visto reducida a sus autores exclusivamente. Así, por ejemplo, si, llegado el caso, se hubiese condenado a la periodista Costanza Miriano por el contenido de su libro «Cásate y sé sumisa: experiencia radical para mujeres sin miedo», conforme al artículo 510.1 b) seguramente habría de serlo también la editorial Nuevo Inicio del Arzobispado de Granada que la publicó y, en su caso, también los libreros que hubiesen vendido ejemplares de la obra. Asimismo, si conforme a la nueva redacción del artículo 510.1 a) CP se hubiese estimado que el artículo del obispo de Alcalá de Henares, D. Juan Antonio Reig Pla, titulado «Llamar a las cosas por su nombre. Un verdadero reto para los católicos» contenía un mensaje de odio, habría entonces, conforme al artículo 510.1 b) CP, que condenar igualmente al director del medio digital Infovaticana que lo publicó. En la misma línea, y para ir cerrando la ejemplificación, en el hipotético caso de que este mismo prelado hubiese sido condenado por un delito de odio por algunas de las expresiones por él empleadas en el transcurso de una homilía pronunciada con motivo de la celebración del Viernes Santo, previsiblemente lo habría sido también, conforme al artículo 510.1 b) CP, el

la Constitución (art. 510 CP) por los que habían sido condenados (STS 259/2011, de 12 de abril). El Tribunal Supremo sostuvo entonces que los hechos probados — difusión de ideas favorables al régimen nazi, que en ocasiones incluían justificaciones del genocidio, y de contenido discriminatorio y excluyente para grupos raciales, étnicos o religiosos-, con relación a la actividad propia de editores o libreros, no constituían acciones delictivas «al no poder identificarse como una provocación o incitación directa a la discriminación, al odio o a la violencia contra grupos o asociaciones por los motivos expresados en el artículo 510 del Código Penal; y al no poder afirmarse tampoco, que mediante la difusión de ideas o doctrinas justificadoras el (sic) genocidio a través de la edición, distribución o venta genérica de libros o revistas, constituyan una incitación indirecta a la comisión de actos constitutivos de tal delito, o una conducta creadora de un clima de hostilidad contra los mencionados grupos susceptible, por sus características, de concretarse en actos específicos de violencia contra aquellos» (FD 1. 15). 
director del diario digital Religión en Libertad, medio que días después publicó una entrevista en la que el Sr. Reig Pla explicaba el sentido de su homilía, e incluso también RTVE que había retransmitido en directo la ceremonia religiosa.

Cierto es, no obstante, que en el momento de escribir estas líneas no han recaído condenas, o al menos no tenemos noticia de ello, sobre miembros relevantes de alguna confesión religiosa por la manifestación de posibles expresiones de odio por razones de sexo, orientación o identidad sexual, o por razones de género, de acuerdo con la nueva regulación introducida en 2015. Pero también lo es que la nueva configuración del tipo penal, en particular la notable expansión de la conducta típica según hemos constatado, en el futuro podría propiciar una nueva orientación en la línea jurisprudencial descrita que dejase expedito el paso a eventuales condenas no sólo a los autores de esos posibles mensajes incitadores o favorecedores del odio, sino también a los que los difunden, aun cuando lo hagan sin identificarse o adherirse expresamente a los mismos, y para los que, además, está prevista —e insistimos en ello—la misma pena que para los autores de tales mensaje de odio.

Así las cosas, no es de extrañar que un sector de la doctrina haya solicitado la supresión del artículo 510.1 b) por representar un ataque a la libertad ideológica y al derecho a expresar y difundir libremente los pensamientos, ideas y opiniones, a la producción y creación literaria, artística, etc. ${ }^{45}$, y por constituir «un emblema de la censura, no sólo criticable por la inseguridad de sus fundamentos, su imprecisa delimitación y la utilización de demasiados conceptos indeterminados que sancionan participaciones no delictivas sino por representar uno de los mayores ataques a la libertad de expresión que se conocen» ${ }^{46}$.

\subsection{La creciente amplitud e indeterminación del discurso de odio y sus riesgos}

\subsubsection{El aventurado tránsito de la acción intolerante a la idea intolerante}

Esta sustancial ampliación de la conducta típica a la que nos venimos refiriendo resulta propiciada en buena medida también por la indeterminación del concepto del discurso de odio, que está lejos de estar bien delimitado tanto normativa ${ }^{47}$ como jurisprudencialmente.

45 GARrocho SAlCEDO, A. M. y PORTIlla CONTRERAS, G., (2013). «Delitos de incitación al odio, la hostilidad, la discriminación o la violencia», Álvarez García, F.J., (dir.), Dopico Gómez-Aller, J., (coord.), Estudio crítico sobre el Anteproyecto de Reforma Penal de 2012, Valencia: 1. . edic., Tirant lo Blanch, p. 937.

46 PORTILLA CONTRERAS, «La represión penal del 'discurso del odio'», pp. 377-378, cit. en nota núm. 30 .

47 Vid la Recomendación núm. R(97)20, de 30 de octubre de 1997, del Comité de Ministros del Consejo de Europa a los estados miembros sobre el «empleo de discurso de odio», y la Recomendación General núm. 15, de 8 de diciembre de 2015, sobre Líneas de Actuación para combatir el discurso de odio, de la Comisión Europea contra el Racismo y la Intolerancia (ECRI) del Consejo de Europa.

(C) UNED. Revista de Derecho Politico 
Según se ha tenido ya ocasión de señalar, la conducta típica descrita en el Código Penal con anterioridad a su reforma de 2015 requería que el discurso de odio incitase directamente a la violencia, a la discriminación o al odio. Recuérdese que tanto si se concebía el antiguo artículo $510 \mathrm{CP}$ como un acto preparatorio (art. $18 \mathrm{CP}$ ) o bien como un tipo autónomo, en ambos casos se exigía que las expresiones de odio tuviesen un carácter incitador directo, esto es, claro e inequívoco. Y en ambos casos, cuando el discurso incitase manifiestamente a la comisión de una acción lesiva prohibida (no así, en cambio, cuando la incitación tuviese por objeto el odio, que no es siquiera un ilícito), la conducta típica podría someterse a un juicio ex ante de peligrosidad abstracta, pero también, cuando ese juicio incluyese la ponderación del específico riesgo que para el bien jurídico protegido comportase el particular contexto ${ }^{48}$ en que tal discurso fuese emitido, a un juicio de peligrosidad concreta que juzgue en cada caso la real y efectiva puesta en peligro del bien jurídico.

En este último caso, el enfoque del tratamiento de las expresiones de odio se aproximaría bastante al seguido por el Tribunal Supremo norteamericano con la aplicación del célebre test del clear and present danger, que exigía para superarlo que aquellas palabras de odio pusiesen en riesgo de lesión evidente y altamente probable $\mathrm{y}$ de forma inminente al bien jurídico protegido, precisamente atendiendo al contexto en que aquellas habían sido proferidas ${ }^{49}$. Algunas de las resoluciones judiciales comentadas en el apartado 1 de este trabajo destilaban de algún modo este planteamiento jurisprudencial, propiciado también por la legislación penal previa a la reforma que, aunque no exenta de matices, posibilitaba la aproximación del riesgo de lesión al bien jurídico objeto de protección. Aunque bien es cierto, sin embargo, que no era esta la orientación seguida, con carácter general, por el Tribunal Europeo de Derechos Humanos (TEDH) ${ }^{50}$.

48 Al respecto son de utilidad las aportaciones del test de relevancia que se propone en el denominado Plan de Acción de Rabat, que ofrece una serie de criterios para efectuar el análisis contextual de las conductas de incitación a fin de discriminar las más graves y, por ello, merecedoras de reproche penal (Rabat Plan of Action on the probibition of advocacy of national, racial or religious hatred that constitutes incitement to discrimination, hostility or violence. Conclusions and recommendations emanating from the four regional expert workshops organised by OHCHR, in 2011, and adopted by experts at the meeting in Rabat, Morocco, on 5 October 2012. Disponible en https://www.ohchr.org/Documents/Issues/Opinion/SeminarRabat/Rabat_draft_outcome.pdf [último acceso: septiembre 2020]. Vid. también el Memorándum explicativo de la Recomendación General núm. 15, de 8 de diciembre de 2015, sobre Líneas de Actuación para combatir el discurso de odio, de la Comisión Europea contra el Racismo y la Intolerancia (ECRI) del Consejo de Europa, § 16.

49 La formulación original del test se debió al ingenio jurídico del juez Oliver Wendell Holmes en Schenck v. United States, 249 U.S. 47 (1919), 51-52. Fue progresivamente nutriéndose de un corpus teórico propiciado por los votos particulares del propio Holmes y de Louis Brandeis en Abrams v. United States, 250 U.S. 616 (1919), Gitlow v. New York, 268 U.S. 652 (1925), o Whitney v. California, 274 U.S. 357 (1927). Y terminaría por alcanzar su configuración más acabada en Brandenburg v. Obio, 395 U.S. 444 (1969). Por todos, ARIAS CASTAÑO, A., (2018). Clear and present danger test: la libertad de expresión en los límites de la democracia, Madrid: Marcial Pons.

50 No obstante, ha habido casos en los que, a través de sus votos particulares, algunos jueces del TEDH han reclamado con relación al discurso de odio la realización de un juicio de peligrosidad 
La ruta seguida por el legislador y la jurisprudencia nacional, así como por el TEDH, con relación a las expresiones de odio será, sin embargo, una bien distinta. En la evolución de la misma, que pasamos a continuación a examinar, se aprecia una configuración del delito del discurso de odio que comporta un adelantamiento aun mayor de la barrera punitiva y una correlativa y progresiva minoración de la carga incitadora hasta prácticamente su completa supresión como elemento consustancial al discurso de odio, observándose, de este modo, en tal evolución un amplio (y peligroso) deslizamiento de la concepción del discurso de odio como aquel que propende de un modo u otro a una acción intolerante a otra que lo identifica pura y simplemente con la idea intolerante.

Como ya se ha tenido ocasión de señalar, la STC 235/2007 dará entrada a las incitaciones indirectas como un posible elemento conformador del discurso del odio, al respaldar la constitucionalidad del reproche penal de las conductas justificadoras del genocidio en el caso de que tal justificación supusiese un modo de incitación indirecta a su perpetración. Pero, además, añade el Tribunal, la constitucionalidad de la tipicidad de tales conductas se justifica cuando con ellas se persiga una suerte de provocación mediata al odio hacia determinados grupos, de tal modo que represente un peligro cierto de generar un clima de violencia y hostilidad contra esos grupos que, a su vez, pueda desencadenar acciones lesivas o el peligro de acciones lesivas contra los miembros de esos grupos (FJ 9). En este último caso, el contenido de injusto (la antijuridicidad) de estas conductas radicaría en la potencialidad en abstracto de esos comportamientos para generar el peligro para los bienes jurídicos protegidos, no siendo necesario no ya que se llegue a producir una lesión del bien jurídico que se pretende proteger, sino que ni siquiera el resultado de peligro (en este caso el clima de violencia u hostilidad) para el mismo ha de ser probado. Se efectuaría, por tanto, un juicio de peligro hipotético o potencial, o de peligro abstracto-concreto; juicio que excluye el peligro o el riesgo de lesión y que atiende únicamente a la potencialidad lesiva de la conducta, es decir, si esta constituye un comportamiento idóneo para

concreta basado en el contexto en el que aquel se difunde [vid., por ejemplo, Zana contra Turquía, de 25 noviembre de 1997, §§ 59-60 y, en especial, la opinión parcialmente disidente de la juez Palm en los casos Sürek contra Turquía y Sürek (núm. 3) contra Turquía; en estos dos mismos casos, la opinión parcialmente disidente común a los jueces Tulkens, Casadevall y Greve; la opinión concordante común a los jueces Palm, Tulkens, Fischbach y Greve en Baskaya y Okçuoglu contra Turquía; la opinión concordante común a los jueces Palm, Tulkens, Fischbach, Casadevall y Greve en Sürek y Özdemir contra Turquí, Arslan contra Turquí, Okçuoglu contra Turquí, Sürek (núm. 4) contra Turquía; Polat contra Turquía, Karatas contra Turquía, Erdogdu e Ince contra Turquía, Gerger contra Turquía, Ceylan contra Turquía; o la opinión parcialmente disidente del juez Fischbach en Sürek (núm. 3) contra Turquía, todos ellos de 8 julio de 1999\}; e incluso pura y simplemente la aplicación del test del clear and present danger [vid. las opiniones concordantes del juez Bonello en los casos Baskaya y Okçuoglu contra Turquía, Sürek y Özdemir contra Turquí, Sürek (núm. 2) contra Turquí, Arslan contra Turquí; Okçuoglu contra Turquí; Sürek (núm. 4) contra Turquí, Polat contra Turquía, Karatas contra Turquía, Erdogdu e Ince contra Turquía, Gerger contra Turquía, Ceylan contra Turquía; sus opiniones parcialmente disidentes en Sürek contra Turquía, Sürek (núm. 3) contra Turquía; o la opinión parcialmente disidente del juez Maruste en Sürek (núm. 3) contra Turquía, todos ellos de 8 de julio de 1999]. 
producir peligro para el bien jurídico protegido, siendo esta idoneidad un elemento normativo del tipo objetivo que necesariamente deberá concurrir y ser constatado judicialmente. Ello, sin embargo, además de un adelantamiento de la instancia penal a la que antes nos referíamos, presenta evidentes dificultades de encaje con los principios de lesividad u ofensividad de las conductas típicas, lo que es particularmente problemático en aquellas que, como en el caso que nos ocupa, están relacionadas con los delitos de expresión.

Tal vez por ello, el voto particular que formula la magistrada Adela Asua a la STC 177/2015, de 22 de julio, y al que se adhiere el magistrado Fernando Valdés, sostiene que «el reflejo emocional de hostilidad» que pudiese desencadenar las expresiones de odio, la creación de un clima de violencia u hostilidad, debe ser constatado y verificado, de suerte que constituya un resultado de peligro concreto, el cual, además, invocando el test del clear and present danger, debiera representar un riesgo de lesión del bien jurídico protegido evidente, acuciante e inminente. Sin embargo, este voto particular, por lo demás muy atinado a nuestro juicio, parece pasar por alto que las exigencias del test del clear and present danger se imputan a las expresiones de odio y al contexto en que son proferidas en cuanto resultado de un peligro concreto y no a la creación de un supuesto clima de violencia, pues en ese caso tal clima suplantaría a las expresiones de odio como objeto de aplicación del test y estas — las expresiones odiosas- constituirían tan solo un peligro hipotético y mediato para los bienes jurídicos protegidos. Y, por otra parte, los delitos de clima se acomodan a la configuración de las modalidades delictivas de peligro hipotético en los que, como recuerda el Tribunal Supremo, «no se tipifica en sentido propio un resultado concreto de peligro, sino un comportamiento idóneo para producir peligro para el bien jurídico protegido», de modo que no se «requiere la concreción del peligro en proximidad de amenaza para un bien determinado», sino que bastaría únicamente «la producción de un estado de riesgo pero desde la perspectiva meramente ex ante». Y aun cuando — prosigue el TS - esta «tipificación se asimila a la de los tipos de resultado en la medida que aquel estado de riesgo ha de valorarse en cuanto resultado separado de la conducta», sin embargo, «[e]llo no impide que la existencia del delito se constate por la mera concurrencia de la conducta típica sin que la verificación deba extenderse a la valoración de ese resultado, que resulta implícito en la tipificación del comportamiento por el legislador». (STS 141/2008, 8 de abril de 2008, FD 4).

Esta compatibilidad de la estructura típica del discurso de odio con un juicio de peligrosidad hipotética o potencial, que terminaría también por plasmar el legislador de reforma en 2015, ya había sido apuntada, como se acaba de señalar, por la STC 235/2007 y posteriormente acogida por la STS 259/2011. En esta última sentencia, el Tribunal Supremo estimó que la conducta consistente en la difusión de ideas o doctrinas que de un modo u otro justifiquen la ejecución de cualquiera de las conductas constitutivas del delito de genocidio, únicamente podrá reputarse como provocación al odio contra determinados grupos cuando tal «difusión, atendiendo a la forma y el ámbito en que se lleva a cabo y a lo que se difunde, implique un peligro 
cierto de generar un clima de hostilidad que pueda concretarse en actos específicos de violencia, odio o discriminación contra aquellos grupos o sus integrantes como tales», o lo que es lo mismo, suponga «la creación de un clima de opinión o de sentimientos que den lugar a un peligro cierto de comisión de actos concretos de discriminación, odio o violencia contra los grupos o los integrantes de los mismos». (FD 1. ${ }^{\circ}$ ). A lo que añade el TS: «No es preciso un peligro concreto, siendo suficiente [...] el peligro potencial o hipotético [...], según el cual lo que importa es la capacidad de la conducta para crear el peligro relevante». Y concluye: «No se trata de exigir la concurrencia de un contexto de crisis, en el que los bienes jurídicos ya estuvieran en peligro, que resultaría incrementado por la conducta cuestionada, sino de examinar la potencialidad de la conducta para la creación del peligro». (FD 1. ${ }^{\circ} 8$ ).

Este enfoque será recogido también por la STC 112/2016, de 20 de junio. En efecto, en esta última sentencia el Alto Tribunal sostendrá que la justificación de actos terroristas o de sus autores, en cuanto manifestación del discurso de odio, requiere la creación de «una situación de riesgo para las personas o derechos de terceros o para el propio sistema de libertades» (FJ 3). Esta situación de riesgo, además, puede ser propiciada o alentada indirectamente por las expresiones de odio (FJ 4). Pero esa incitación indirecta, que supone siempre llevar a cabo una acción que ex ante suponga elevar el riesgo de lesión de los bienes jurídicos protegidos, no incrementaría aquí un peligro concreto de lesión, sino el riesgo de creación de «un determinado caldo de cultivo, una atmósfera o ambiente social» que pudiese desencadenar, a su vez, en un futuro más o menos próximo, acciones violentas (FJ 6). La carga incitadora del discurso se debilita o difumina tanto que no generaría por sí mismo un peligro, abstracto o concreto, sino un peligro hipotético o potencial en la medida en que «la conducta del recurrente era idónea para contribuir a perpetuar una situación de violencia» y, además, en el contexto o en el ambiente social en el que se insertaba su discurso, «resultaba mucho más fácil que prendiera la llama» (FJ 6; cursivas nuestras). Ahora bien, la referencia efectuada por el Tribunal al contexto en el que se emite el discurso odioso, y en coherencia con la línea argumental aquí seguida, no se hace a fin de realizar sobre el mismo un juicio de peligrosidad concreta para los bienes jurídicos protegidos, sino para llevar a cabo un juicio de peligrosidad hipotética o potencial en cuanto que tal mensaje inserto en ese particular contexto puede ser potencialmente idóneo para generar un determinado clima social, antesala mismo del delito.

Este adelantamiento de la barrera punitiva y el correlativo debilitamiento de la fuerza incitadora del discurso odioso es recogido también, incluso de forma más intensa y reforzada, en la jurisprudencia del TEDH. De este modo, el Tribunal europeo sostendrá en el caso Féret contra Bélgica que la carga incitadora de las expresiones de odio, o sea, su orientación dirigida a ganar voluntades a fin de que terceros acaben por realizar directamente acciones lesivas (en el caso de las violentas o discriminatorias) o de forma indirecta (en el supuesto de inocular el odio en determinados sectores de la sociedad) contra determinados grupos, no es un elemento consustancial a las mismas. O para ser más precisos, el TEDH estima, por una parte, que la incitación a 
la comisión de actos violentos contra grupos vulnerables no es un componente inescindible del discurso de odio y, de otra parte, que la incitación a la discriminación en el discurso odioso (racista) se presume. Por ello, todo discurso racista es per se un discurso de odio ${ }^{51}$. De este modo, y en esta evolución que bascula de la acción a la idea intolerante a la que nos venimos refiriendo, el juicio de peligrosidad abstracta para los bienes jurídicos concernidos prescinde del componente incitador del discurso de odio para rebajarlo a su mero contenido ${ }^{52}$, que en sí mismo es odioso con independencia de las consecuencias fácticas a las que tendencialmente incite, lo cual, además, se acompaña de una ampliación y difuminación de los bienes jurídicos protegidos que lo justifique, tales como «la paz social y la estabilidad política en los Estados democráticos ${ }^{53}$, probablemente demasiado inconsistentes 0 , incluso, peligrosamente demasiado inconsistentes como para justificar el riesgo abstracto de su lesión una injerencia legítima en el ejercicio de la libertad de expresión ${ }^{54}$.

Con todo, sin embargo, el TEDH sí vendría a exigir una carga incitadora violenta cuando el objeto del discurso odioso tuviese una naturaleza política (STEDH, Karakoyun y Turan c Turquía, de 11 diciembre de 2007, \$30) o, en términos más exactos, cuando exteriorice aversión, hostilidad u odio hacia el sistema constitucional, los valores democráticos, el Estado o sus instituciones. La libertad de expresión, por tanto, gozaría de un ámbito de protección más amplio cuando tuviese por objeto un discurso eminentemente político, incluso cuando este fuese un discurso político

51 Caso Féret contra Bélgica, 16 de julio de 2009, $\$ \$ 73,70$ y 78.

52 Esta era precisamente la orientación que guiaba al voto particular formulado por el magistrado Andrés Martínez Arrieta a la STS 259/2011, en el que, a fin de motivar su disensión respecto a la decisión de la Sala Segunda del TS de casar y anular la sentencia dictada por la Audiencia Provincial de Barcelona - el caso de la Librería Kalki anteriormente citado- y de absolver a los condenados, puede leerse que «[l]a estructura de estos tipos penales [la de los que punen el discurso de odio] participa de la naturaleza de los delitos de peligro. Aunque existan colectivos afectados por la agresión, eso no afecta a la estructura del tipo de peligro, bastando para su realización con la generación de ese peligro que se concreta en el mensaje con un contenido propio del «discurso del odio» que lleva implícito el peligro al que se refiere el tipo». Por ello — continúa el magistrado discrepante- la antijuridicidad del discurso de odio no precisa de «una exigencia que vaya más allá del discurso que contiene un mensaje odioso que, por sí mismo, es peligroso a la convivencia». (cursivas nuestras). Este planteamiento tampoco ha sido del todo ajeno, aun cuando haya tenido una repercusión más bien episódica, a la jurisprudencia del TS de los EE.UU. El test del clear and present danger fue aplicado en algunas ocasiones de un modo más flexible y menos exigente, atendiendo sobre todo a la gravedad del mal que se quería evitar, de manera que un mal grave podía justificar que se penalizase un discurso aunque el riesgo de que se materializase ese mal que se pretendía evitar no fuese inminente. [Vid. Dennis v. United States, 341 U.S. 494 (1951), 509-510, y también el voto particular del juez Douglas, 584. En buena medida, la reformulación en este caso del test obedeció a la influencia del juez Learned Hand, (Ibíd., 510-511 y 571) que había postulado como test alternativo el direct incitement approach, centrado en el contenido y la naturaleza de las palabras empleadas].

53 STDH, caso Féret contra Bélgica, 16 de julio de 2009, $\$ 73$.

54 Acerca de los riesgos que comporta la identificación del simple discurso «peligroso» con el discurso de odio, conviene la lectura de la contundente opinión disidente a la sentencia Féret contra Bélgica del juez Andràs Sajó, y que suscriben los jueces Zagrebelsky y Tsotsoria. 
odioso $^{55}$. Podría decirse que se observa aquí cierto paralelismo con el distinto grado de protección que el TEDH dispensaba en algún momento de su evolución jurisprudencial a la libertad de expresión dependiendo de si tenía por objeto un mensaje de naturaleza política o religiosa, y a la que nos referíamos en otra parte de este trabajo, concretamente en el apartado 2.2, in fine.

El Tribunal europeo, en cambio, prescinde de la necesidad de acreditar esa carga incitadora violenta cuando el discurso de odio tiene por destinatario a un grupo vulnerable, incluso cuando aquel se inserta en un contexto eminentemente político ${ }^{56}$. Volviendo ahora a la cuestión que nos ocupa, el TEDH, recogiendo la jurisprudencia asentada en Féret contra Bélgica, sostendrá en Vejdeland y otros contra Suecia, de 9 de febrero de 2012, por una parte, que el discurso homofóbico, en cuanto estigmatiza a un determinado grupo vulnerable, concretamente a una minoría sexual, es en sí mismo un discurso de odio, que no requiere adicionalmente una incitación o una llamada a un acto de violencia u otros delitos y, de otra, que «la discriminación basada en la orientación sexual es tan grave como la discriminación basada en la 'raza, origen o color'» (§55).

Así las cosas, el Tribunal procede de nuevo a efectuar sobre las expresiones de odio una suerte de juicio de peligrosidad abstracta sobre los bienes jurídicos protegidos — la igualdad y la seguridad, entre otros, del grupo diana en cuestión, en este caso el colectivo homosexual - , pero con un ligero — aunque en absoluto baladí - matiz: ese juicio no se ciñe únicamente al contenido del mensaje que, como ya se ha señalado, puede estar desprovisto de carga incitadora, sino que se extiende también al contexto en el que tal mensaje se inserta. Concretamente, la circunstancia de que el mensaje homofóbico tuviese como destinatarios estudiantes menores de edad en un centro educativo conforma también, junto con su contenido, los elementos valorativos de aquel juicio y justifica, en este caso, que el Tribunal estimase que la injerencia en el ejercicio de la libertad de expresión de las personas que distribuyeron en un instituto esos panfletos contra los homosexuales podía ser considerada como necesaria en una sociedad democrática para la protección de la reputación y de los derechos ajenos ( $\S$ 49-59). Pero dejaba abierta la duda de si en otras circunstancias, en definitiva, en otro contexto, hubiese llegado a la misma conclusión.

55 En esta línea jurisprudencial se inscribiría, por cierto, la reciente STC 35/2020, de 25 de febrero. Esta orientación seguida por la jurisprudencia del Tribunal europeo en este concreto ámbito del discurso de naturaleza política evoca a la que, aun con excepciones y matices, ha venido manteniendo con carácter general, y también en el ámbito político, la Corte Suprema de EE.UU.; así, por ejemplo, Watts v. United States, 394 U.S. 705 (1969) o Matal v. Tam 582 U.S. _ (2017). [Vid. PRESNO LINERA, M. Á, (2019). «El discurso del odio contra las minorías sexuales: respuestas penales y administrativas», Matia Portilla, F.J., Elvira Perales, A. y Arroyo Gil, A., (dir.), La protección de los derechos fundamentales de las personas LGTBI, Valencia: 1 edic., Tirant lo Blanch, pp. 284-285].

56 Vid. TEDH Le Pen contra Francia (dec.), de 20 de abril de 2010, y STEDH caso Féret contra Bélgica, de 16 de julio de 2009, \$§ 69-73 y 76-78. De forma análoga, STEDH caso Balsytè-Lideikienè contra Lituania, de 4 de noviembre de 2008, $\$$ 70-86. 
De hecho, esta es en el fondo la motivación que subyace y justifica la opinión concurrente del juez Yudkivska, y que suscribe también el juez Villiger, en Vejdeland y otros contra Suecia. En ella lo que a fin de cuentas se sostiene es la conveniencia, a fin de «consolidar un enfoque sobre el discurso de odio contra los homosexuales», de dirigir aquel juicio de peligrosidad única y exclusivamente al contenido del mensaje, prescindiendo del contexto en el que aquel hubiese sido transmitido. Los pasquines repartidos en el centro educativo describían la homosexualidad como «una conducta sexual desviada» y acusaban a los homosexuales de «tener un efecto moralmente destructivo en el seno de la sociedad». En opinión del juez Yudkivska esas acusaciones, por sí solas y al margen de cualquier contexto, encajaban perfectamente en la categoría del discurso de odio. Si antes en Féret contra Bélgica el discurso racista había sido calificado, en sí mismo, como un discurso de odio, ahora el discurso homofóbico debiera haber sido catalogado igualmente, por sí solo, como un discurso de odio. Repárese en que, grosso modo, estas expresiones homofóbicas son, en esencia, perfectamente intercambiables con cualquiera de las manifestaciones que acerca de la homosexualidad habían efectuado algunas autoridades eclesiásticas españolas y que se recogen al inicio de este trabajo. No sería probablemente muy aventurado conjeturar que, a la vista de la estructura del tipo delictivo tipificado en el artículo 510 CP tras la reforma de 2015, una eventual condena por un delito de incitación al odio por análogas manifestaciones públicas homofóbicas podría superar el control de convencionalidad (ex art. 10 CEDH) efectuado por el TEDH, sobre todo si este finalmente acabase transitando en la dirección apuntada en este voto concurrente, lo que por otra parte no sería más que extender al discurso homofóbico la doctrina asentada para el discurso racista en Féret contra Bélgica.

Una vez más, el TEDH sigue aquí una orientación distinta a la del Tribunal Supremo estadounidense, que ha considerado que el simple discurso contrario, o incluso hostil, al colectivo homosexual, en tanto no represente, atendiendo también al contexto en el que se produce, un peligro concreto, evidente, inminente o muy probable de desencadenar acciones lesivas contra alguno o algunos de sus miembros, estará amparado por la Primera Enmienda y tiene derecho a protección ${ }^{57}$.

Excedería con mucho el objeto de este trabajo tratar de explorar las razones de varia índole que explican o arrojan luz sobre este distinto enfoque de las jurisdicciones norteamericana y europea acerca de la libertad de expresión y su mayor o menor permeabilidad respecto a los distintos tipos de discurso de odio ${ }^{58}$. Con carácter general, la propia concepción de los derechos fundamentales difiere en ambas tradiciones constitucionales ${ }^{59}$. En EE.UU. los derechos fundamentales se conciben

57 Snyder vs. Phelps y otros, 562 U.S. 443 (2011).

58 Vid. PRESNO LINERA, M. A. y TERUEL LOZANO, G. M., (2017). La libertad de expresión en América y Europa, Lisboa: Juruá, y ALCÁCER GUIRAO, R., (2015). «Víctimas y disidentes. El ‘discurso del odio’ en EE.UU. y Europa», Revista española de derecho constitucional, 35, núm. 103: 45-86.

59 Siguiendo a Zagrebelsky, cabría distinguir dos modos distintos de concebir la constitucionalización de los derechos fundamentales. Una concepción subjetivista, la americana, y otra objetivista, la europea, y más concretamente francesa, que, a su vez, constituyen el sustrato teórico e ideológico de dos 
como ámbitos de autonomía o libertad individual en los que el Estado debe abstenerse de intervenir y permanecer neutral e inactivo. Los derechos se entienden como derechos subjetivos que, en términos generales y salvo excepciones que, además, responden a una lógica distinta a la europea, carecen de naturaleza prestacional, justamente para asegurar la inacción del Estado. En Europa, en cambio, los derechos, además de subjetivos, algunos de ellos —en todo caso notablemente más que en EE.UU. y de forma creciente- participan de un carácter prestacional, y tienen asimismo una dimensión objetiva. Los derechos no son sólo, aunque también, naturalmente, espacios reservados a la autonomía individual, sino asimismo normas que expresan y encarnan valores objetivos del ordenamiento jurídico. En el caso de la libertad de expresión, el libre ejercicio individual de este derecho — dimensión subjetiva - facilitaría la existencia de una opinión pública libre que, a su vez, es condición indispensable del pluralismo político y del funcionamiento mismo del Estado democrático — dimensión objetiva—. Esta dimensión objetiva del derecho a la libertad de expresión ciertamente amplía su perímetro de cobertura en la operación de su delimitación con relación a otros derechos y bienes constitucionales con los que puede concurrir. Pero al mismo tiempo esta funcionalización del derecho fundamental ${ }^{60}$ puede producir el efecto contrario, al excluir del objeto del derecho aquellas expresiones — como las expresiones de odio- que en nada contribuyen a la formación de esa opinión pública libre.

Por otra parte, hay razones históricas y políticas de sobra conocidas que explican el entendimiento en Europa de la democracia como democracia militante, es decir, como un sistema político que es activamente beligerante con las ideas intolerantes. La democracia estadounidense, en cambio, desembarazada de esos condicionamientos histórico-políticos y por su concepción misma de los derechos fundamentales que se acaba apenas de apuntar, es más abierta y tolerante con las ideas intolerantes, pues lo contrario, según esta visión, esto es, «suprimir la libertad de expresión, incluida la expresión subversiva, [implicaría] siempre una supresión parcial de la democracia» ${ }^{61}$.

modos distintos de interpretar los derechos y su función: los que se corresponderían con los que el insigne jurista italiano denomina humanismo laico y humanismo cristiano. El primero, de inspiración liberal, acentúa el componente subjetivo de los derechos, cuya función esencial es la de crear un orden a partir de la libertad. En cambio, el humanismo cristiano, que gravita sobre la vertiente objetiva (o institucional) de los derechos, atribuye a estos la función esencial de reestablecer el orden alterado por la libertad, es decir, por la libre interacción de las distintas libertades individuales. Lo que mejor explicaría o arrojaría más luz sobre las diferencias entre ambas concepciones son los valores hacia las que se orientan: la libertad y la justicia respectivamente. [ZAGREBELSKY, G., (2007). El Derecho dúctil: ley, derechos, justicia, Madrid: 7. a edic., Trotta, pp. 75-92]. Este distinto enfoque —el norteamericano y el europeo-, centrado ya específicamente en los problemas relativos al hate speech y la libertad de expresión, puede seguirse, respectivamente, en DWORKIN, R., (1985). A matter of principle, Cambridge (Massachusetts) and London (England): Harvard University Press, y WALDRON, J., (2012). The harm in hate speech, Cambridge (Massachusetts): Harvard University Press.

${ }^{60}$ SOLOZÁBAL ECHAVARRÍA, J. J., (1988). «Aspectos constitucionales de la libertad de expresión y el derecho a la información», Revista española de derecho constitucional, 8, núm. 23, pp. 144-146.

61 RAWLS, J., (1996). Sobre las libertades, Barcelona: Paidós, p. 103. 
La plasmación jurídica de esa versión de democracia entendida como democracia militante vendría a ser el artículo $17 \mathrm{CEDH}$, la «cláusula contra el abuso de derecho», en virtud de la cual, en ningún caso el ejercicio de un derecho - la libertad de expresión en el caso que nos ocupa- podrá comportar la destrucción o limitaciones más amplias de las previstas de los derechos y libertades reconocidos en el Convenio. El TEDH ha recurrido a esta cláusula para excluir de raíz de la protección del Convenio, sin entrar siquiera en el fondo del asunto, los discursos de odio negacionistas del Holocausto (aunque no, sin embargo, de otros genocidios) y también algunos discursos racistas y xenófobos. En cambio, no la ha empleado con relación a los discursos de odio relativos a la orientación sexual. Y, por otra parte, como se ha señalado, el Tribunal europeo, lejos de seguir pautas propias de un modelo de democracia militante, ha tutelado discursos políticos odiosos dirigidos contra el orden constitucional y los valores democráticos.

En cambio, como también antes se ha tenido oportunidad de indicar, el TEDH ha utilizado parámetros propios de la democracia militante (aunque no por la vía de la aplicación del art. $17 \mathrm{CEDH}$, sino de la exclusión del objeto de protección de la libertad de expresión ex art. $10 \mathrm{CEDH}$ ) con relación a los discursos o expresiones de odio dirigidos contra grupos vulnerables - y en lo que a nosotros aquí interesa, contra minorías sexuales - en cuanto representan un ataque inaceptable contra valores democráticos como la dignidad o la igualdad de derechos. Prima facie, aunque este planteamiento ciertamente resulta extraño a nuestro modelo constitucional abierto, ajeno a la idea de democracia militante, podría en cambio encontrar acomodo en él ya que la CE sí prevé expresamente la protección de grupos vulnerables ${ }^{62}$.

\subsubsection{El difícil encaje constitucional de esta configuración punitiva de las expresiones de odio}

Más dudas, en cambio, suscita la constitucionalidad de estas expresiones aversivas contra las minorías sexuales a tenor, según se ha visto, de la configuración del tipo penal que las prevé. El adelantamiento de la intervención penal, que justifica el peligro de lesión de los bienes jurídicos protegidos únicamente a través de sucesivos encadenamientos de hipotéticos supuestos fácticos, y la reducción e incluso la supresión o presunción iuris et de iure de la carga incitadora del discurso odioso a los que nos venimos refiriendo, no parece que tengan fácil acomodo con los principios que informan y limitan el ius puniendi del Estado.

En efecto, ni la configuración legal ni tampoco la propia evolución jurisprudencial del TEDH en este ámbito parecen tener un fácil encaje con el principio penal de intervención mínima que, a su vez, se proyecta en los principios de subsidiariedad o

62 Vid. PRESNO LINERA, «El discurso del odio contra las minorías sexuales: respuestas penales y administrativas», p. 286, cit. en nota núm. 55. 
ultima ratio ${ }^{63} \mathrm{y}$ de fragmentariedad. Sin entrar ahora en el debate de si estos principios, junto con otros a los que debe someterse el ius puniendi estatal - como el principio de lesividad, cuyas exigencias, por cierto, y como ya se ha indicado, no parece colmar el artículo $510 \mathrm{CP}$ - pueden o no integrar el principio de proporcionalidad en sentido amplio $^{64}$, la restricción en la libertad de expresión que el legislador penal ha efectuado por medio de la tipificación de las expresiones de odio tras la reforma de 2015 no parece tampoco sujetarse, de aplicarse al menos en la mayoría de los supuestos típicos analizados en este trabajo, a las tres exigencias clásicas —idoneidad, necesidad y proporcionalidad en sentido estricto- del principio de proporcionalidad en sentido más preciso. Y ello aun cuando la utilización de este principio para controlar constitucionalmente las decisiones del legislador, atendiendo al margen de libre apreciación del mismo en la operación de creación y concreción, como en este caso, de los límites de los derechos fundamentales y a su vinculación negativa a la Constitución, deba llevarse a cabo «de forma y con intensidad cualitativamente distinta a las aplicadas a los órganos encargados de interpretar y aplicar las leyes» (STC 55/1996, de 28 de marzo, FJ 6). A ello habría que añadir el efecto desaliento ${ }^{65}$ que la sanción penal de estas conductas, en general, o en su caso de la mayoría — no de todas, pues en algunos casos, como el del imán de Fuengirola, aquella sanción, en nuestra opinión, estaría justificada- de las descritas en este trabajo, en particular, podría tener en el futuro sobre sus autores o sobre aquellos otros que, como ellos, pretendan expresar un punto de vista similar. Sobre todo, como se ha podido constatar tras la reforma de 2015, si se atiende a la desmesurada amplitud de las conductas típicas que, a su vez, no se compadece demasiado bien con el principio de taxatividad penal. Todo ello, en fin, no parece desbaratar, sino más bien lo contrario, «el riesgo de hacer del Derecho penal un factor de disuasión del ejercicio de la libertad de expresión, lo que, sin duda, resulta indeseable en el Estado democrático» (STC 35/2020, de 25 de febrero, FJ 4$)^{66}$.

Pero tampoco desde una concepción estricta de los derechos fundamentales parece constitucionalmente admisible esta delimitación que del derecho a la libertad de

63 No faltan ejemplos, no obstante, de regulaciones que, aun cuando respetuosas con el principio de subsidiaridad penal al reconducir a otras ramas del derecho — concretamente a la administrativa- la sanción de conductas expresivas de odio por motivos de orientación sexual e identidad y/o expresión de género, son sin embargo de dudosa constitucionalidad, debido a la desmesurada ampliación de las conductas sancionables y la manifiesta desproporción de las sanciones previstas. (Vid. ibíd. pp. 304-309).

64 MIR PUIG, S., (2010). «El principio de proporcionalidad como fundamento constitucional de límites materiales del Derecho penal», Mir Puig, S. y Queralt Jiménez, J.J., (dir.), Fernández Bautista, S., (coord.), Constitución y principios del derecho penal: Algunas bases constitucionales, Valencia: 1. a edic., Tirant lo Blanch, p. 74.

65 Entre otras, SSTC 190/1996, de 25 de noviembre, FJ 3 a); 136/1999, de 20 de julio, FFJJ 20 y 29 c); 177/2015, de 22 de julio, FJ, 2 d), y 112/2016, de 20 de junio, FJ 2 iii).

66 Bien es cierto, sin embargo, que, si dirigimos nuestra atención no tanto sobre los emisores de las expresiones de odio sino sobre sus destinatarios, podría apreciarse que aquellas podrían llegar a producir sobre los grupos vulnerables a los que van dirigidas un efecto silenciador, limitando por esta vía la libertad de expresión de sus integrantes y dificultando su participación en la vida pública. Vid. FISS, O. M., (1999). La ironía de la libertad de expresión, Barcelona: 1. a edic., Gedisa. 
expresión efectúa el legislador penal. El adelantamiento de la barrera punitiva y el vaciamiento de la carga incitadora del discurso odioso aleja cada vez más la punición de la posible acción intolerante en la misma medida que la aproxima a la de la idea intolerante. Idea que, además, como se ha visto, se somete a un juicio de peligrosidad abstracta, pudiendo incluso desvincularse del concreto contexto en que se emite; o a un juicio de peligrosidad potencial o hipotética en el que la situación de peligro ni siquiera es un elemento del tipo, de suerte que lo que parece penalizarse y, por tanto, excluirse de las expectativas de conducta cubiertas por el derecho fundamental a la libertad de expresión es la mera transmisión de este tipo de ideas (odiosas). Ahora bien, esta libre transmisión de ideas integra justamente el contenido esencial del derecho a la libertad de expresión ${ }^{67}$, ya se conciba ese contenido como aquellas facultades o posibilidades de actuación necesarias para que el derecho fundamental sea recognoscible como tal en un determinado momento histórico y sin las cuales se desnaturalizaría, o para cumplir su función de garante de ciertos bienes jurídicos o intereses constitucionales (STC 11/1981, de 8 de abril, FJ 8), o bien como un contenido abstractamente definido en la Constitución que el legislador, al concretarlo, debe respetar escrupulosamente ${ }^{68}$, pues, de lo contrario, el derecho se volvería irreconocible y se imposibilitaría, en la práctica, su ejercicio. Tampoco parece, pues, que esta operación de delimitación del derecho a la libertad de expresión por la vía de la concreción de sus límites (lógicos o inmanentes) realizada por el legislador pudiese superar, desde esta perspectiva, un examen de constitucionalidad.

No cabe duda de que este tipo de expresiones en general, y en particular - y en lo que concierne a este trabajo- las dirigidas contra mujeres y minorías sexuales, provocan rechazo e incluso repulsión, al menos en la mayoría de la sociedad, y desde luego no facilitan y pueden ser efectivamente nocivas para la convivencia. Pero una cosa es que esa mayoría trate de evitar que este tipo de discursos se conviertan en hegemónicos o dominantes, lo cual constituye un objetivo político legítimo y deseable, y otra distinta es que esa misma mayoría se arrogue la facultad de excluir del debate público este tipo de discursos o ideas execrables. La distancia que media entre una y otra alternativa es exactamente la misma que existe entre la implementación de ciertas políticas públicas (educación cívica, etc.) orientadas, por así decirlo, a generar una inmunidad de grupo frente a este tipo de expresiones, y el recurso a la represión penal para extirparlas del espacio público de debate. Ello no quiere decir, sin

67 Como ha tenido ocasión de recordar el TC, «a las normas penales les está vedado invadir el contenido constitucionalmente garantizado de los derechos fundamentales». Y es por eso que «[1]a libertad de configuración del legislador penal encuentra su límite en el contenido esencial del derecho a la libertad de expresión, de tal modo que [...] nuestro ordenamiento constitucional no permite la tipificación como delito de la mera transmisión de ideas, ni siquiera en los casos en que se trate de ideas execrables por resultar contrarias a la dignidad humana que constituye el fundamento de todos los derechos que recoge la Constitución y, por ende, de nuestro sistema político» (STC 235/2007, de 7 de noviembre, FJ 6, cursivas nuestras).

68 BASTIDA FREIJEDO et al., Teoría general de los derechos fundamentales en la Constitución española de 1978, pp. 133-141, cit. en nota núm. 14. 
embargo, que, en aquellos supuestos — como en algunos de los descritos en este trabajo- en los que este tipo de discursos provocan ciertamente un riesgo de lesión de los bienes jurídicos protegidos no esté justificada la utilización de la vía penal. No lo está, en cambio, a nuestro juicio, cuando — como en la mayoría de los casos con los que se inicia este texto- el hacerlo supone tipificar conductas a pesar del alejamiento y difuminación del riesgo de lesión de los bienes jurídicos objeto de protección que tales conductas ocasionan, lo cual, por una parte, repugna a los principios que informan el derecho penal y, por otra, violenta la configuración constitucional del derecho de libertad de expresión.

Title:

Can hateful religious speech for reasons of gender, orientation and sexual identity be considered a hate crime?

\section{Summary}

1. THE HYPOTHETICAL RELIGIOUS SPEECH OF HATE FOR REASONS OF GENDER, SEX, ORIENTATION OR SEXUAL IDENTITY: SOME EXAMPLES. 1.1. The religious speech of some Islamic ministers of worship about the role of women. 1.2. The religious message of some Catholic ecclesiastical authorities, or supported by them, on issues of gender, orientation and sexual identity. 2. THE COVERAGE OF THE RELIGIOUS SPEECH WITH PUBLIC RELEVANCE: IDEOLOGICAL, RELIGIOUS FREEDOM AND FREEDOM OF EXPRESSION. 2.1. The institutional aspect of religious freedom and freedom of expression: the right of religious confessions to disclose and propagate their own creed through social media and networks. 2.2. Religious and speech freedom: relationships and limits. 3. RELIGIOUS AND SPEECH FREEDOM AND HATE SPEECH. 3.1. The expansion of criminal conduct: from provocation to direct and indirect incitement and mere acts of favor and the spreading the hate speech. 3.1.1. The provocative idea as an unequivocally incitement idea. 3.1.2. The weakening of the inciting component of the hateful or hostile idea. 3.1.2.1. The expression of hate speech. 3.1.2.2. Spreading hate speech. 3.2. The increasing scope and indeterminacy of hate speech and its risks. 3.2.1. The risky transition from intolerant action to intolerant idea. 3.2.2. The difficult constitutional fit of this punitive configuration of hate speech. 


\title{
Resumen:
}

En la actualidad se constata una creciente demanda de diversos sectores sociales, políticos y jurídicos que reclama una intensificación de la persecución penal de determinadas expresiones dirigidas contra minorías y grupos vulnerables. En particular, en este trabajo se examinan discursos o escritos que, aun cuando prima facie gozarían de la cobertura de las libertades religiosa y de expresión, podrían incitar al odio por razón de género, orientación e identidad sexual y, en consecuencia, resultar penalmente perseguibles. En el trabajo se sostiene, sin embargo, que la nueva configuración del tipo penal previsto en el artículo $510 \mathrm{CP}$, la orientación jurisprudencial seguida por el Tribunal Constitucional y por el Tribunal Europeo de Derechos Humanos podrían ocasionar una contracción de los márgenes de las libertades religiosa y de expresión de dudosa constitucionalidad.

\begin{abstract}
:
At the present time, there is a growing demand from various social, political and legal sectors calling for an intensification of the criminal prosecution of certain expressions directed against minorities and vulnerable groups. In particular, this work examines speeches or writings that, even if prima facie they would enjoy the coverage of religious freedom and freedom of speech, could incite hatred on the grounds of gender, orientation and sexual identity and, consequently, be criminally prosecutable. However, the paper maintains that the new configuration of the criminal offense provided for in article $510 \mathrm{CP}$, the jurisprudential orientation followed by the Constitutional Court and the European Court of Human Rights could cause a contraction of the margins of religious freedom and freedom of speech of doubtful constitutionality.
\end{abstract}

Palabras clave:

Libertad de expresión, libertad religiosa, derechos fundamentales, delitos de odio, expresiones de odio.

\section{Key Words:}

Freedom of speech, religious freedom, fundamental rights, hate crimes, hate speech. 